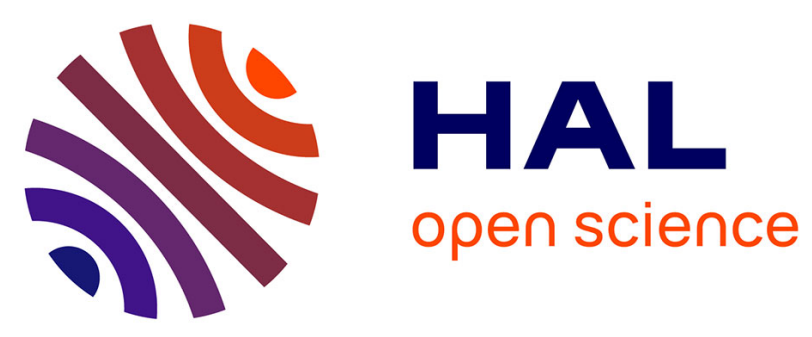

\title{
Effect of Diffusion Length in Modeling of Equiaxed Dendritic Solidification under Buoyancy Flow in a Configuration of Hebditch-Hunt Experiment
}

Tao Wang, Sergey Semenov, Engang Wang, Yves Delannoy, Yves Fautrelle, Olga Budenkova

\section{To cite this version:}

Tao Wang, Sergey Semenov, Engang Wang, Yves Delannoy, Yves Fautrelle, et al.. Effect of Diffusion Length in Modeling of Equiaxed Dendritic Solidification under Buoyancy Flow in a Configuration of Hebditch-Hunt Experiment. Metallurgical and Materials Transactions B, In press, 50 (6), pp.30393054. 10.1007/s11663-019-01703-z . hal-02395330

\section{HAL Id: hal-02395330 \\ https://hal.science/hal-02395330}

Submitted on 20 Nov 2020

HAL is a multi-disciplinary open access archive for the deposit and dissemination of scientific research documents, whether they are published or not. The documents may come from teaching and research institutions in France or abroad, or from public or private research centers.
L'archive ouverte pluridisciplinaire HAL, est destinée au dépôt et à la diffusion de documents scientifiques de niveau recherche, publiés ou non, émanant des établissements d'enseignement et de recherche français ou étrangers, des laboratoires publics ou privés. 
1 Effect of Diffusion Length in Modeling of Equiaxed Dendritic

2 Solidification under Buoyancy Flow in a Configuration of

3 Hebditch-Hunt Experiment

4 TAO WANG ${ }^{1,2,3}$, SERGEY SEMENOV $^{2}$, ENGANG WANG $^{1,3}$, YVES DELANNOY $^{2}$, YVES $^{2}$

5 FAUTRELLE ${ }^{2}$, and OLGA BUDENKOVA ${ }^{2}$

6 1) Key Laboratory of Electromagnetic Processing of Materials (Ministry of Education),

7 Northeastern University, No. 3-11, Wenhua Road, Shenyang 110004, P. R. China

8 2) Univ. Grenoble Alpes, CNRS, Grenoble INP, SIMAP, F-38000 Grenoble, France.

9 3) School of Metallurgy, Northeastern University, Shenyang 110004, P. R. China

10 Author's email address:

11 TAO WANG: epm_wangtao@163.com

12 SERGEY SEMENOV: s.semionov_1266@mail.ru

13 ENGANG WANG: egwang@mail.neu.edu.cn

14 YVES DELANNOY: yves.delannoy@ simap.grenoble-inp.fr

15 YVES FAUTRELLE: Yves.Fautrelle@simap.grenoble-inp.fr

16 OLGA BUDENKOVA: olga.budenkova@simap.grenoble-inp.fr

17 Correspondent: egwang@mail.neu.edu.cn (ENGANG WANG)

T. Wang, S. Semenov, E. Wang, Y. Delannoy, Y. Fautrelle, O. Budenkova, Effect of Diffusion Length in Modeling of Equiaxed Dendritic Solidification under Buoyancy Flow in a Configuration of Hebditch-Hunt Experiment, Metallurgical and Materials Transactions B, 2019, 50 (6), 3039-3054

Version submitted after revision 
ABSTRACT: Modeling of equiaxed solidification is vital for understanding the solidification process of metallic alloys. In this work, an extended literature review is given for the models currently used for equiaxed solidification simulations. Based on this analysis, we present a three-phase multiscale equiaxed solidification model in which some approximations regarding solute transport at microscopic scale are put together in a new way and incorporated into macroscopic transport equations. For the latter, a term relating to the momentum exchange between the two phases is revised, and a modification for the grain packing algorithm is proposed. A modernized model for equiaxed dendrite growth is tested using a case of solidification of $\mathrm{Sn}-5 \mathrm{wt} . \% \mathrm{~Pb}$ alloy in a parallelepiped cavity that mimics the Hebditch-Hunt experiment. The results obtained using two approaches to calculate diffusion length are presented and compared both with each other and with numerical results from elsewhere. It is demonstrated that diffusion

29 length has a crucial effect on the final segregation pattern.

31 KEY WORDS: Equiaxed solidification, Macrosegregation, Diffusion length, Grain growth, Multiphase flow 


\section{Introduction}

Modeling the equiaxed regime for alloy solidification is essential for predicting the structure and composition of solidifying material in the casting process. Indeed, sedimentation or flotation of free equiaxed grains leads to composition inhomogeneity; growth of equiaxed dendrites can block growth of columnar ones either mechanically or by rejected solute and induces columnar to equiaxed transition (CET). ${ }^{[1,2]}$ However, despite serious efforts to develop dedicated numerical models, such simulation remains challenging due to the complexity of coupled multiscale phenomena. Indeed, numerical analysis of equiaxed dendritic solidification accompanied by convective flow basically needs to address the following issues: (1) individual grain growth inside an undercooled melt, which is governed by the mass, heat and chemical species transfers between phases, which, in turn, are affected by grain growth; (2) motion of liquid and growing grains, and corresponding transport of solute concentration, energy and grain number density. Contemporary numerical models propose different approaches to resolve these issues. To provide readers with a clear vision of the differences between the models, an extended review regarding treatment of the aforementioned issues is given in the introduction. Based on this analysis, in section II we present a three-phase multiscale equiaxed solidification model in which some approximations regarding microscopic scale phenomena are put together and incorporated into macroscopic mass, momentum, energy and solute transportation equations in a new way. Particular attention is paid to calculation of diffusion length around the dendrite envelope, which is crucial for grain growth kinetics. Furthermore, the choice of momentum exchange coefficient, the improvements to the grain packing method, and a double time step algorithm are also explained in detail. The proposed model is applied to simulation of the Hebditch-Hunt experiment, which is briefly described in section III. In section IV, the results obtained using two approaches to calculate diffusion length are presented and show us the drastic influence of the diffusion length model on the final segregation pattern. These results are also compared with numerical results that can be found elsewhere.

\section{A. Models for growth of an individual grain accounting for convection}

Regarding diffusive growth of an individual dendrite grain, most models are based on the utilization of three phases as was initially proposed by Thévoz et al. ${ }^{[3]}$. These three phases (see Figure 1) are: the solid dendrite, or $s$-phase; the liquid between the solid dendrite arms, the 
so-called interdendritic liquid, or $d$-phase; and the liquid outside of the dendrite envelope, the so-called extradendritic liquid, or $l$-phase. Each phase is characterized by a corresponding volume fraction and averaged values for velocity, temperature and solute concentration. The liquid concentration at the solid-liquid interface $c_{l}^{*}$ is generally supposed to be equal to the thermodynamic equilibrium concentration, which is related to local temperature through a phase diagram. In most three-phase models, the interdendritic liquid is considered well mixed, and its average solute concentration $c_{d}$ is equal to $c_{l}^{*[4-7]}$. Alternatively, for example in a model by $\mathrm{Wu}$ et al. ${ }^{[8]}$, the value of $c_{d}$ is calculated according to the diffusion rate at both $s-d$ and $l-d$ interfaces, as shown schematically in Figure 1(b). This approach maintains a small gap between $c_{d}$ and $c_{l}^{*}$, avoiding the fluctuation of solute concentration in case of abrupt change in temperature, and thus enhancing model stability under convective flow.

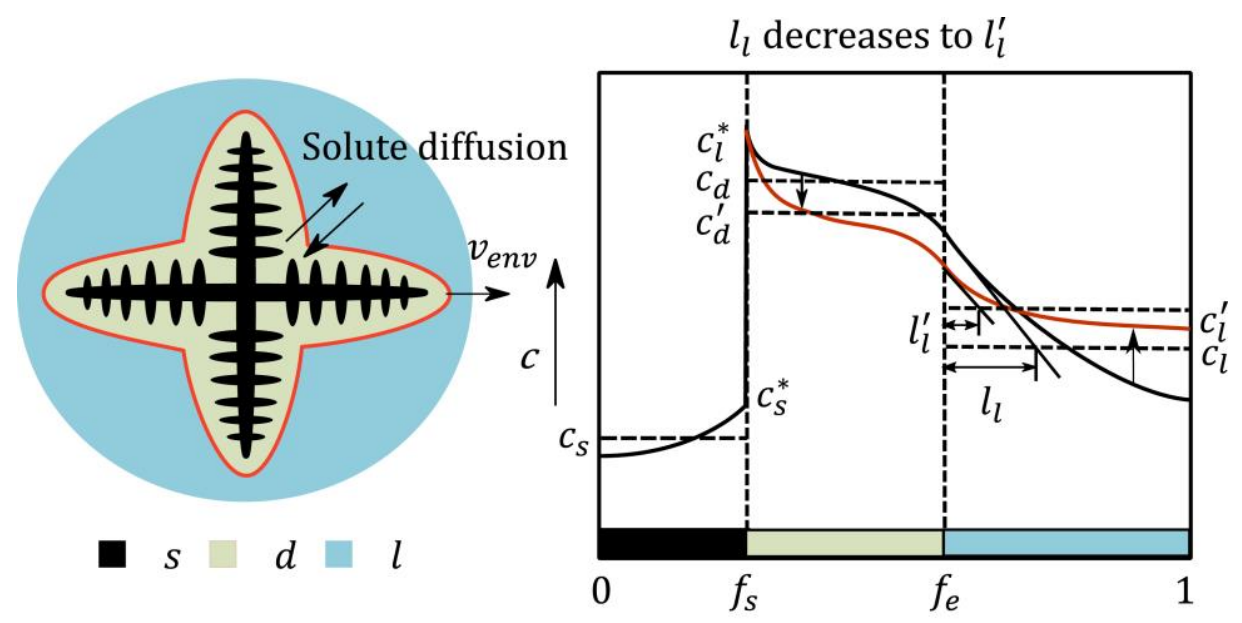

(a)

(b)

Fig. 1-(a) Schematic representation of grain growth with phase assignment, and (b)effect of diffusion length on average solute concentration in each phase.

The transition from the liquid to the solid phase can be seen as a combination of dendrite growth, associated with the elongation of the primary dendrite arms at the expense of the extradendritic liquid, and the lateral growth of secondary arms during which the interdendritic liquid solidifies. In theory, dendrite tip growth velocity can be calculated accounting for the convective flow that leads to cumbersome expressions. ${ }^{[9,10]}$ Therefore, in macroscopic models, it is generally accepted that dendrite tip growth velocity can be estimated using the Lipton-Glicksman-Kurz (LGK) model $^{[11]}$ in steady diffusive growth, or using modified LGK models ${ }^{[12,13]}$ when accounting for 
convection. In the LGK model, tip growth velocity $v_{\text {tip }}$ depends on the constitutional undercooling ahead of the dendrite tip or ahead of a so-called grain envelope. This undercooling corresponds to the local difference between $c_{l}^{*}$ and external liquid concentration $c_{l}$. According to the scheme presented in Figure 1, this difference greatly depends on the diffusion length in $l$-phase denoted by $l_{l}$. A theoretical solution for $l_{l}$ exists for diffusive growth of a single grain under steady conditions ${ }^{[14]}$ that gives:

$$
l_{l}=\frac{D_{l}}{v_{\text {tip }}}
$$

where $D_{l}$ is the solute diffusion coefficient in $l$-phase, and $v_{\text {tip }}$ is the primary dendrite tip velocity. For a spherical envelope, $v_{\text {tip }}$ is also the $l$ - $d$ interface movement velocity relative to grain growth. For a non-spherical envelope, $v_{t i p}$ should be replaced by $v_{e n v}=\phi_{\mathrm{M}} v_{t i p}, \phi_{\mathrm{M}}$ is a shape factor.

This formulation was used by Wu et al. ${ }^{[8]}$ in the equiaxed solidification problem with grain transportation and fluid flow although it does not take into account the intensification of the diffusive flux by convection. It can be assumed that convection leads to a smaller diffusion length than that defined by Eq. [1], i.e. transport of the solute from the $d$-phase to the $l$-phase will be intensified, thus promoting enrichment of the $l$-phase. To take this into account, for example, in a three-phase model by Wang et al. ${ }^{[13]}$ a relative velocity between the $l$ - and the $s$ - phases was introduced in the expression for $l_{l}$. For two-phase models, which can be globular ${ }^{[15-17]}$ or dendritic, ${ }^{[18]}$ there is no distinction between $d$ - and $l$-phases: instead, a liquid phase, or $f$-phase, is considered. In this case, the diffusion length in the $f$-phase is denoted by $l_{f}$. In the two-phase model by Ni et al., ${ }^{[17]}$ the effect of convective flow was accounted for via a Sherwood number, which had to be, however, carefully chosen from experimental data. ${ }^{[19]}$ According to Wang et al., ${ }^{[7]}$ in a dendritic growth of equiaxed grains with spherical envelope shape, diffusion length $l_{l}$ should be smaller than the value given by Eq.[1] to keep a continuous enrichment process of the 1-phase. A similar criterion was used in a non-spherical equiaxed solidification model by replacing tip velocity with an envelope growth velocity. ${ }^{[8]}$ To satisfy this, in the description of mass transport for a single equiaxed crystal moving in an infinite medium, Appolaire et al. ${ }^{[12]}$ used a boundary layer around an equivalent sphere accounting for the convection as $l_{l}$ and then limited its maximum value by the length given in Eq. [1]. The most representative models for diffusion length are grouped in Table I. 
The expression of the momentum exchange or drag force between phases $i$ and $j$, denoted as

$\vec{U}_{i j}^{D}$, depends on the choice of phases that represent macroscopic motion in the system. The phase $j$ related to the dendritic grain can be presented only as the solid dendrite in the liquid (Figure 2(a)), or as a union of the solid dendrite and the interdendritic liquid (grain) in the extradendritic liquid (Figure 2(b)). In the latter case, however, a difference in macroscopic velocities between the solid phase, inter- and extradendritic liquid can be taken into account $\vec{u}_{d} \neq \vec{u}_{l}$ (Figure 2(c)).
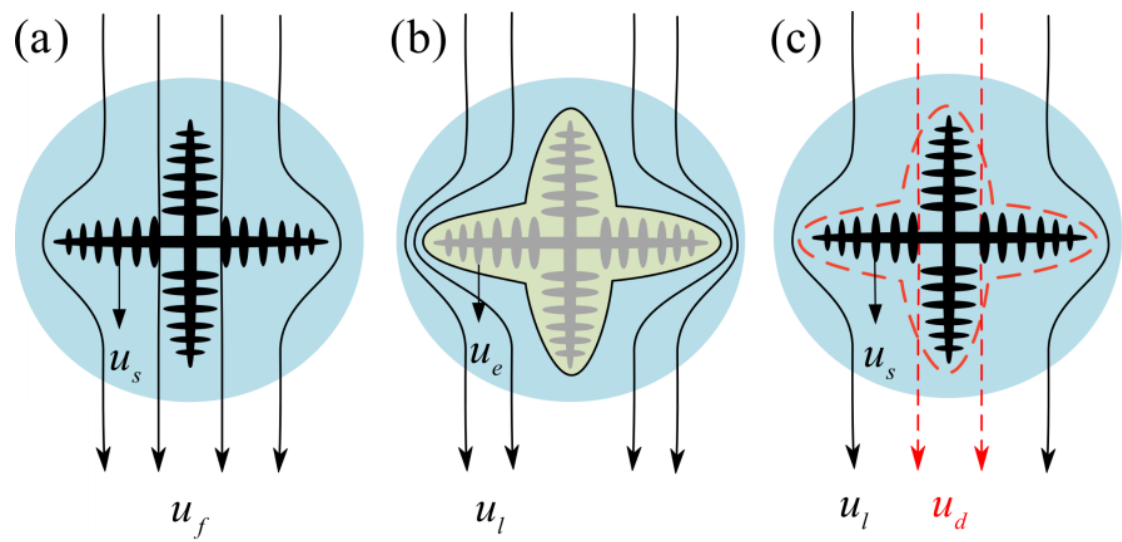

Fig. 2-Schematic figure for different unions of phases: (a) solid dendrite ( $s$ - phase) and liquid phase ( $f$-phase), (b) equiaxed grain phase ( $e$-phase) and extradendritic liquid phase ( $l$-phase), and (c) the solid dendrite ( $s$-phase), inter- and extradendritic liquid phases ( $d$ - and $l$-phases). In an averaged description, the phase $j$ that represents dendrites is generally considered to be a porous medium, due to the complexity of an individual dendrite structure. It is customary to treat the momentum exchange while the liquid phase $i$ is passing through a medium phase $j$ using a generalized exchange coefficient $K_{i j}$ and the difference in phase velocities. $K_{i j}$ can be expressed either via a configuration factor $F_{K}\left(f_{j}, d_{j}\right)$ and permeability $K$ of the solidifying phase, or via another configuration factor $F_{C D}\left(f_{j}, d_{j}\right)$ along with a notion of a drag coefficient $C_{D}$, resulting from consideration of a particle moving through the liquid:

$\vec{U}_{i j}^{D}=K_{i j}\left(\vec{u}_{i}-\vec{u}_{j}\right)=F_{K}\left(f_{j}, d_{j}\right) \frac{\mu_{i}}{K}\left(\vec{u}_{i}-\vec{u}_{j}\right)=F_{C D}\left(f_{j}, d_{j}\right) C_{D} \rho_{l}\left|\vec{u}_{i}-\vec{u}_{j}\right|\left(\vec{u}_{i}-\vec{u}_{j}\right)$

In Eq. [2] both functions $F_{K}\left(f_{j}, d_{j}\right)$ and $F_{C D}\left(f_{j}, d_{j}\right)$ depend on the fraction and characteristic size and sphericity of the particles of phase $j$. Note that the drag coefficient $C_{D}$ can take into account the permeability of phase $j$ and thus that the two configurations indicated above can be 
equivalent. Different approximations for these functions and coefficients (see Table II) can be found in literature.

The most common model, traditionally used for permeability of the mushy zone in columnar dendrite growth, is the Kozeny-Carman relation ${ }^{[20]}$ (Table II), which was formulated for the pressure drop in a laminar flow passing through a stationary packed column. The latter was treated as a bundle of tangled tubes of various cross-sections. This relation was used in the model with two phases and globular equiaxed grains developed by $\mathrm{Wu}$ et al. ${ }^{[21]}$ and further adopted by these authors for the drag force between $l$-phase and $e$-phase $\vec{U}_{l e}^{D}=-\vec{U}_{e l}^{D}$ (Figure 2(b)) in a three-phase model. ${ }^{[22]}$

In another two-phase solidification model with globular equiaxed grains, $\mathrm{Ni}$ et al. ${ }^{[17]}$ used an expression for the drag coefficient $C_{D}$ that accounted for a modification of flow character during the solidification process. For low solid fractions $\left(f_{s}<0.5\right)$ the grains were supposed to move relatively freely in the liquid, i.e. the interfacial momentum balance between the solid and liquid could be presented using Stokes' law for an individual object moving through the liquid. For $f_{s}>0.5$, the solid phase was similar to a packed bed, thus allowing momentum balance to be presented with the Kozeny-Carman expression. A similar approach was adopted by Leriche et al. ${ }^{[4]}$ in a three-phase model. For slurry regions, they applied the model used by Ni et al. ${ }^{[17]}$ but replaced the solid-phase fraction with a grain-phase fraction. For packed regions, a permeability related to secondary arm spacing is applied.

In Wang et al.'s model, ${ }^{[13]}$ the $l$ - and $d$-phases were united as the $f$ - phase: $f_{f}=f_{d}+f_{l}$, yet, the difference between velocities $\vec{u}_{d}$ and $\vec{u}_{l}$ was preserved (Figure 2(c)). An expression for the momentum exchange coefficient $K_{f s}$ (Table II) between $f$ - and $s$-phases was obtained for all solid fractions ranging from 0 to 1 through a general correlation $K_{f s}=\left\{\left[\left(1-f_{l}\right) K_{d s}\right]^{n}+\left(K_{l e}\right)^{n}\right\}^{1 / n}$. In this equation, coefficient $K_{d s}$ was evaluated from the secondary dendrite arm spacing, and coefficient $K_{l e}$ was taken from Happel's approach that considered the viscous flow relative to the bed of spherical particles ${ }^{[23]}$. Wang et al.'s model ${ }^{[13]}$ took into account a shape factor $C_{p}\left(\Phi_{\mathrm{e}}\right)$ for the dendrite grain to provide freedom for estimation of surface area concentration.

In Appolaire et al.'s work ${ }^{[12]}$, another model proposed for the momentum exchange coefficient in a three-phase system was verified with the equiaxed grain sedimentation experiment. Table II gives more details on different models for calculating the momentum exchange coefficient. 
As indicated above, another important phenomenon related to the motion of equiaxed grains is their packing, after which the grains can be considered immovable. However, for the sake of brevity, in this paper we prefer not to discuss the various models used to implement packing phenomena: some references are indicated elsewhere ${ }^{[24]}$. A description of the procedures used in the model is given below in section II-C.

\section{Description of the present model}

The present model is based on three phases, which consist of the liquid outside of the envelope of equiaxed dendrite ( $l$-phase), the interdendritic liquid ( $d$-phase), and the solid dendrite ( $s$-phase) (Figure 2(b)). The phase fractions satisfy the following constraint: $f_{d}+f_{s}+f_{l}=1$. A union of the solid dendrite and the interdendrite liquid makes the grain phase $f_{d}+f_{s}=f_{e}$. The solid and grain phase should appear in the volume once nucleation has occurred. Nucleation is assumed to occur instantaneously once local constitutional undercooling is greater than nucleation undercooling $\Delta T>\Delta T_{n u c l}$, or if the local grain number density $n$ drops below $1 \mathrm{~m}^{-3[16]}$. The latter condition is used to avoid null grain number density that leads to significant numerical errors. During the growth stage, the primary dendrite tip velocity $v_{\text {tip }}$ calculated by the LGK model ${ }^{[11]}$ is multiplied by a shape factor $\phi_{\mathrm{M}}$ to obtain the envelope growth velocity $v_{\text {env }}$. In this work, the value for $\phi_{\mathrm{M}}$ is given as $0.683^{[22]}$ assuming an octahedral grain envelope shape, although its exact value needs to be measured based on experimental results. Dendritic envelope surface area concentration $S_{e}^{M}$ is evaluated based on a spherical envelope shape, as in most works ${ }^{[6,14,16,25]}$. Solidification of the interdendritic liquid is governed by solute diffusion in the interdendritic liquid region. Diffusion length inside the interdendritic liquid is assumed to be half of the distance between the secondary dendrite arms (given in Table IV), whereas solid back diffusion is ignored. Regarding the macroscopic multiphase flow, it is assumed that the interdendritic liquid and the solid dendrite share the same velocity field, i.e. the solid phase moves together with some amount of the liquid around it. In the conservation equations, all densities are constant and equal to the reference density, that is $\rho_{l}=\rho_{s}=\rho_{e}=\rho_{d}=\rho_{\text {ref }}$. Similar to Založnik and Combeau, ${ }^{[16]}$ to model the sedimentation phenomenon, in the buoyancy term, a constant difference between the solid phase density and a reference density is introduced. The Boussinesq approximation accounts for solutal and thermal convection in the liquid phase. While the grain growth model and macroscopic 
conservation equations are similar to those described elsewhere, ${ }^{[22]}$ we propose a new combination of parameters to model the diffusion length between the inter- and extradendrtic liquid. Further, a Happel model is used for implementation of the drag force, and a new grain packing algorithm is proposed. The reasons for these choices and their crucial effect on the evolution of the solidification processes are explained in detail below. Conservation equations, source terms, and some auxiliary expressions, are summarized in Table III, while the main physical parameters are provided in Table IV.

\section{A. Diffusion length model}

Determination of diffusion length, especially the diffusion length around the envelope in the extradendritic liquid $l_{l}$, drastically affects numerical results as it links phase transition with the enrichment of the extradendritic liquid. According to Eq. [21] and Figure 1, if $l_{l}$ decreases, the solute flux through the envelope intensifies, and the concentration difference between the interand extradendritic liquid decreases if the average concentration is conserved within the volume corresponding to the final grain size. Consequently, a smaller solutal undercooling ahead of the dendrite tip leads to a smaller dendrite growth rate (Eq. [34]). This means that the solid fraction within grain phase $f_{s}^{e}$ increases and could promote the sedimentation or floatation of equiaxed grains. Different methods, proposed for calculation of $l_{l}$, are discussed above in the introduction, and provided in Table I. All of them emphasize several factors, namely dendrite tip velocity, current and final diameter of the grain (or envelope), and relative velocity between the grain and the liquid phases. In the present work, the diffusion length proposed by $\mathrm{Ni}$ et al. ${ }^{[17]}$ is adapted for the three-phase model, and, following the work of Appolaire et al. ${ }^{[12]}$, we limit its maximum value by the length given in Eq. [1], replacing $v_{t i p}$ by $v_{e n v}$ since a non-spherical envelope shape is considered.

$$
l_{l}=\min \left[\frac{d_{e}}{2}\left(\frac{1}{1-\left(1-f_{l}\right)^{\frac{1}{3}}}+\frac{S c^{\frac{1}{3}} R e^{a}}{3 f_{l}}\right)^{-1}, \frac{D_{l}}{v_{\text {env }}}\right]
$$

where $S c=\mu_{l} /\left(\rho D_{l}\right)$ is the Schmidt number, $R e=\left|\vec{u}_{l}-\vec{u}_{e}\right|\left(\rho f_{l} d_{e}\right) / \mu_{l}$ is a local Reynolds number calculated with the envelope diameter $d_{e}$, and $a=\left(2 R e^{0.28}+4.65\right) / 3\left(R e^{0.28}+4.65\right)$. In the first term inside the max operator in Eq. [35], the fraction $1 /\left(1-\left(1-f_{l}\right)^{1 / 3}\right)$ accounts for the effect of solute interaction, while the term $S c^{1 / 3} R e^{a} /\left(3 f_{l}\right)$ describes the effect of convection around the equiaxed grain envelope. In order to quantitatively illustrate the 
contribution of each individual physical phenomenon (accounted for in the Eq. [35]) and the influence of the diffusion length model on phase evolution, a numerical study was conducted for a zero-dimension solidifying system in which temperature is assumed to be uniform in the calculation domain and governed by the following equation: ${ }^{[14]} c_{p} \dot{T}=\mathrm{L}\left(d f_{s}\right) / d t-c_{p} m\left(d c_{l}^{*}\right) /$ $d t$. In this case $c_{p}$ is capacity, $\mathrm{L}$ is latent heat, $m$ is the slope of liquidus in the phase diagram, and $\dot{T}=1 \mathrm{~K} / s$ is the imposed cooling rate. Calculations are carried out for the $\mathrm{Sn}-5 \mathrm{wt} \% \mathrm{~Pb}$ alloy, the same as that investigated in section III, the properties of which are given in Table IV. The total concentration of the solute in the calculation is conserved.

Four different diffusion length models are compared: the one given by Eq. [35] and three others given by Eqs. [36] through [38]:

$l_{l}=\frac{D_{l}}{v_{e n v}}$

$l_{l}=\min \left[\frac{d_{e}}{2}, \frac{D_{l}}{v_{e n v}}\right]$

$l_{l}=\min \left[\frac{d_{e}}{2}\left(\frac{1}{1-\left(1-f_{l}\right)^{\frac{1}{3}}}\right)^{-1}, \frac{D_{l}}{v_{\text {env }}}\right]$

In case 1, we use a diffusion length that is determined by envelope growth velocity (Eq. [36]). In case 2, based on Eq. [37], the model assumes that, at the initial growth stage, the thickness of the diffusion boundary layer around the envelope is comparable with the grain's radius. In case 3 (Eq. [38]), the solute interaction is taken into account, and thus diffusion length can decrease at the later solidification stage. It should be noted that these phenomena were already taken into account in the models proposed by Martorano et al. ${ }^{[26]}$ and Ciobanas et al. ${ }^{[5]}$ However, their models are not considered here because they did not deal with convection. Finally, in case 4, where we use Eq. [35], the convection around envelope is included in the model in addition to the previously described effects. In order to use Eq. [35], some additional parameters are required.

Grain number density is given a value of $10^{9} / \mathrm{m}^{3}$ to determine final grain size. Velocity difference $\left|\vec{u}_{l}-\vec{u}_{e}\right|$ is imposed to be $0.1 \mathrm{~mm} / \mathrm{s}$, assuming a weak liquid flow around the grains. Results of simulations are presented in Figure 3. 


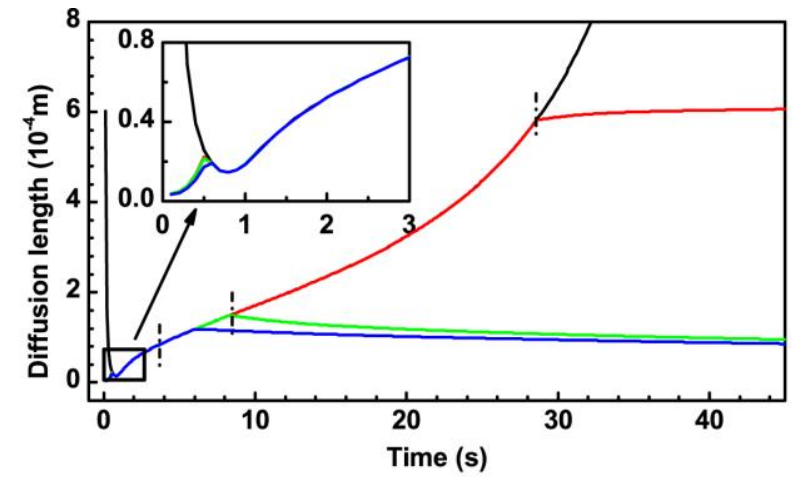

(a)

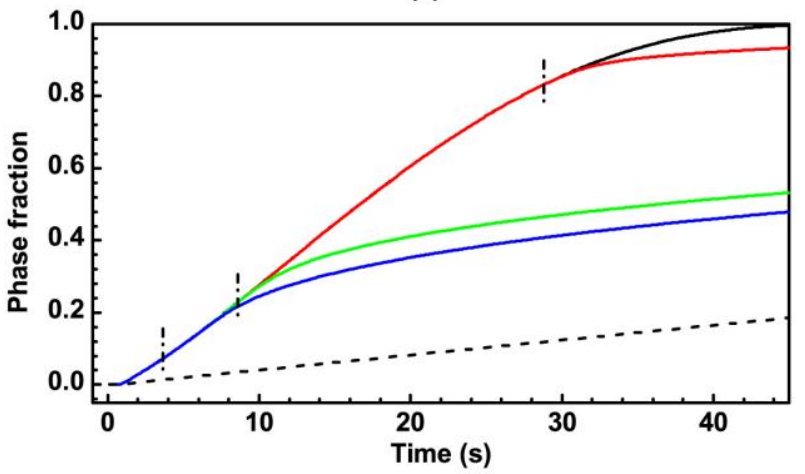

(b)

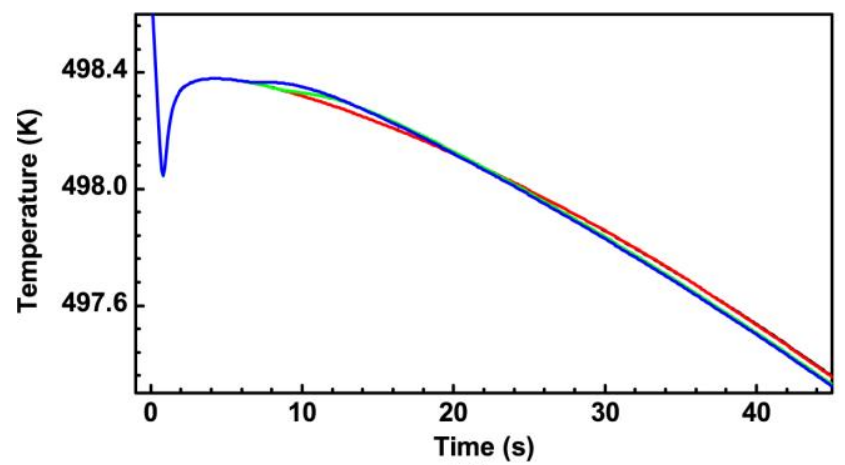

(c)
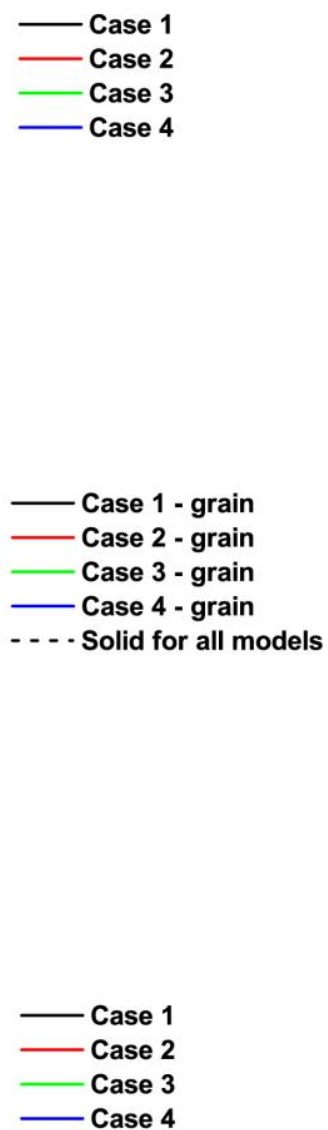

Fig. 3- Solidification in a zero dimension uniformly solidifying system obtained with different models (Eqs. [35] through [38]) for diffusion length $l_{l}$ : (a) variation of diffusion length $l_{l}$ in time, (b) evolution of the solid and grain fractions and (c) temperature evolution.

At the early stage $(t<0.6 \mathrm{~s})$ of grain growth, grain size is small while the value of $D_{l} / v_{\text {env }}$ is high. Hence, in the expression of Eqs. [35], [37] and [38], the first term in the bracket prevails, and case 1 differs from the 3 other cases: see the insert in Figure 3(a). Meanwhile, the effect of

254 convection and solute interaction is negligible. A second growth stage can be identified during a

255 time period from $0.6 \mathrm{~s}$ to $2.9 \mathrm{~s}$, when $v_{\text {env }}$ increases rapidly, and the second expression in Eqs.

256 [35], [37] and [38] becomes smaller. Consequently, the value of the diffusion length for all 4 cases 257 is calculated with the same expression, and evolution of phase fractions (Figure 3(b)) and 
temperature (Figure 3(c)) in all four cases is almost equivalent. After $2.9 \mathrm{~s}$, the four cases show obvious differences. For case 1 and case 2, diffusion length increases in a similar way until approximately 29 s since $v_{\text {env }}$ decreases. In case 3 and case 4 , solutal interaction and convective effect become important. Therefore, although in both Eqs. [35] and [38], the first term in the brackets is chosen, the diffusion length calculated with Eq. [35] is smaller due to convection, that also affects the evolution of the grain fraction (Figure 3(b)). It is interesting to note that the diffusion length evolution observed by Torabi Rad et al. ${ }^{[27]}$ experienced similar 3 stages as in cases 2 through 4 , although that simulation was made for another alloy system and under a different cooling condition. A remarkable difference in envelope growth is observed between case 1 and case 4 after $45 \mathrm{~s}$ of solidification. In the former, the envelopes of neighboring grains impinge $\left(f_{e} \approx 1\right)$, and further solidification occurs in the interdendritic liquid, yet the grain fraction in case 4 is only 0.48 . Such a difference can greatly influence the solidification process and macrosegregation pattern. Regarding the macroscale model, the effect of convective flow on equiaxed solidification is even more complex since the average solute concentration for a given grain may also change due to solute or grain transportation at the macroscale. This effect is shown in section IV.

\section{B. Momentum exchange coefficient}

Based on a direct comparison of the non-dimensional momentum exchange coefficients $K_{l e} d_{e}^{2} / \mu_{l}$ calculated with the Happel model $^{[23]}$ and the Carman-Kozeny model ${ }^{[20]}$ (Figure 4(a)), the difference between them could be thought to be minor. Yet, a simple demonstration can be made with the settling velocity $u_{e}$ of grains falling in a stationary liquid. This can be calculated from the equilibrium between the gravitational force and the friction from the liquid as $u_{e}=$ $\Delta \rho \mathrm{g} / K_{\mathrm{le}}$. We estimated this velocity for different grain fractions using the grain number density $n=10^{9} \mathrm{~m}^{-3}$ (for calculation of the grain diameter $d_{e}$ ) and the density difference $\Delta \rho=$ $100 \mathrm{~kg} / \mathrm{m}^{3}$. Figure 4 (b) presents the results obtained with the two models, while the velocity calculated with the classical Stokes' drag force is also included for comparison. For a large grain fraction region, i.e. $f_{e}>0.4$, the Happel model and Kozeny-Carman model predict similar settling velocity, which approaches zero as the amount of liquid decreases. However, for grain fractions approaching zero, the settling velocity calculated with the Happel model also moves to 
zero, similarly to the case with the Stokes' law, while use of the Kozeny-Carman equation gives a

velocity value moving to infinity. One can conclude that the Happel model provides a good

approximation both for the free-particle regime, also including very small nuclei, and the packed bed regime. It should be noted that the model used by Wang et al. ${ }^{[13]}$ (Table II) is reduced to the

Happel model if the partition of the inter- and extradendritic liquid phases is not considered.
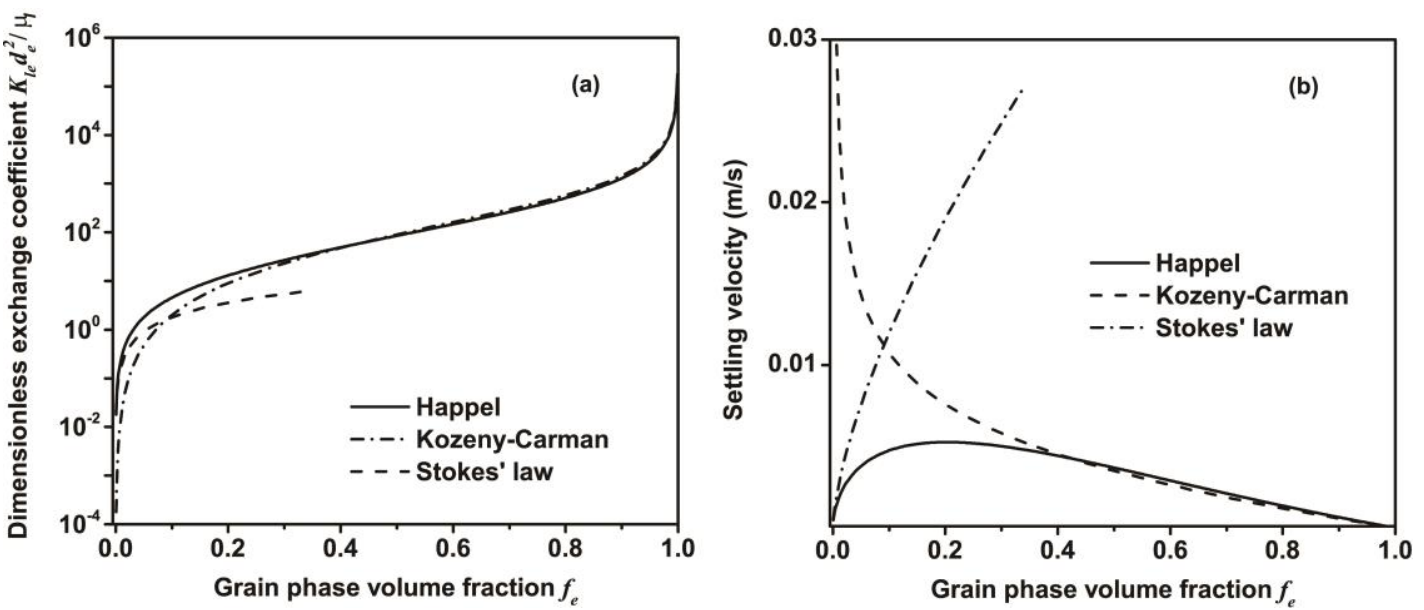

Fig. 4 -Comparison of (a) dimensionless momentum exchange coefficient between $l$ - and $e$ phases and (b) settling velocity between different models.

\section{Grain packing method}

During solidification, the free-floating equiaxed grains impinge before being packed in a rigid structure similar to columnar grains. In numerical models, this transition is treated with a packing fraction limit, which can be associated either with grain fraction $f_{p}^{e}$ or with solid fraction $f_{p}^{s}$, depending on the phases whose relative motion is considered. Generally, it is assumed that for a freely moving equiaxed grain, whose volume fraction increases to the packing fraction limit, its velocity should drop to zero. It is widely accepted that the packing fraction limit for the grain phase is $f_{p}^{e}=0.637^{[4,22,28]}$, which is an approximation of the closest packing fraction of randomly arranged monodisperse spheres. For solid fraction, the limit is lower and accepted to be in the range $f_{p}^{\text {s }}=0.1 \sim 0.5,{ }^{[24,29,30]}$. A more complex morphology of the solid dendrites makes them easier to form a packed structure. ${ }^{[31]}$ A widely used packing condition is that $f_{e}$ is higher than $f_{p}^{e}$. However, even if $f_{e} \geq f_{p}^{e}$, grains cannot be made rigid when they are in the middle of a non-rigid domain, as a group of them could still sediment or float up or be dragged. Thus, in order to avoid unphysical system behavior, the second packing condition is introduced to the model, 
which assumes that the grains to be packed should have a rigid neighbor upon which to be attached. A grain packing status marker $i_{p}$ is adopted to identify whether or not the grains in a calculation cell should be packed. During initialization, a zero value is assigned to $i_{p}$ in each calculation cell. If the cell of interest is adjacent to the wall or has at least one packed neighboring cell, its $i_{p}$ value is changed to 1 . For the cell marked with $i_{p}=1$, once $f_{e} \geq f_{p}^{e}$ is satisfied, the grains get packed and the marker $i_{p}$ is set to 2 , which means that the grain phase motion must be stopped. This procedure is repeated at each time integration step.

\section{Implementation of the solution algorithm}

To reduce simulation time, the processes occurring at macroscopic and microscopic scales are modeled with different time step sizes, as shown in Figure 5.

For each intensive medium property $\Psi$, representing phase fraction, solute concentration, temperature or grain number density, a balance equation can generally be written as: $(d(\rho \Psi)) /$ $d \tau+\nabla(\rho \vec{u} \Psi)=\nabla\left(\lambda_{\Psi} \nabla \Psi\right)+S_{\Psi}$, where the convection term $\nabla(\rho \vec{u} \Psi)$ and the diffusion term $\nabla\left(\lambda_{\Psi} \nabla \Psi\right)$ represent macroscale transport phenomena. The source term $S_{\Psi}$ is mainly induced by microscale evolution, including the nucleation and exchange of mass, energy and solute between phases. A double time step method is based on an assumption that microscopic exchange only has a slight influence on macroscopic transportation. A larger time step size $\Delta t$, used for calculation of macroscopic transportation, is divided into $N$ sub-steps $\Delta \tau=\Delta t / N$ used for time integration of the microscopic exchange rate.

Microscopic exchange is calculated locally by omitting the macroscale transport terms giving $(d(\rho \Psi)) / d \tau=S_{\Psi}$. Each variable is initialized as $\Psi_{0}$, which is the transport solution from the last time step. The value at sub-step $i$ is calculated with the first-order time integration scheme using data from the previous sub-step $i-1: \rho \Psi_{i}=\rho \Psi_{i-1}+S_{\Psi, i-1} \Delta \tau$. In each sub-step, at first an amount of nuclei $\left(N_{\Phi} \Delta \tau\right) / N$ is added, then the rate of phase transition is determined, after that, the solute concentration and enthalpy content are calculated for each phase. Finally, the values of $\sum_{i=1}^{N} S_{\Psi, i}=\rho\left(\Psi_{N}-\Psi_{0}\right) / \Delta \mathrm{t}$ are recorded and then used as source terms for solving macroscopic transport equations, including multiphase flow field and transport of energy and solute concentration. These macroscopic transport equations are solved by ANSYS FLUENT® software. In current research, we use the time step size $\Delta t$ of $0.005 \mathrm{~s}$ and the number of sub-steps $N$ of 20. 


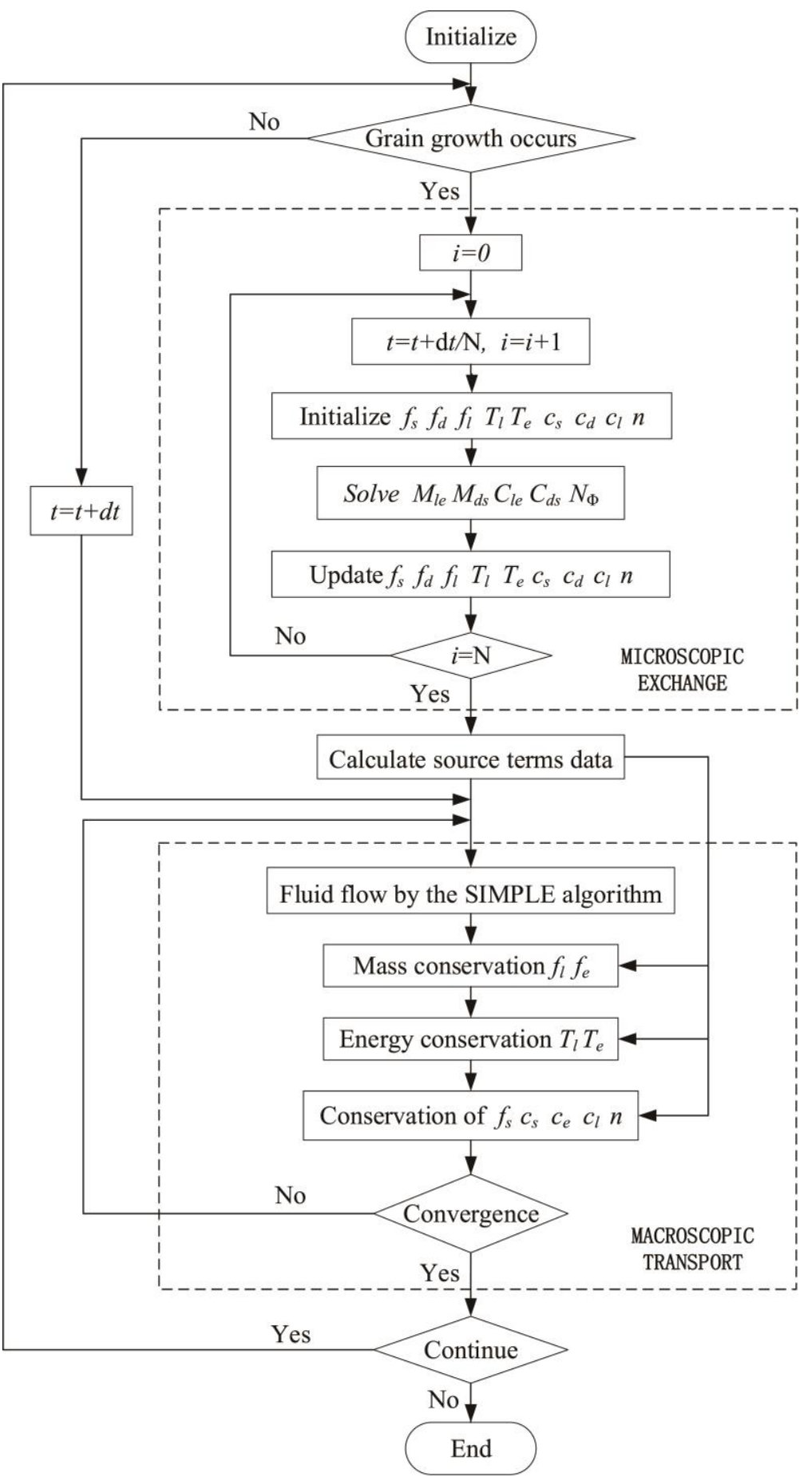

342 Fig. 5-Solution algorithm scheme.

\section{Description of the simulated case}

345 The numerical model described above is applied to solidification of a binary alloy, which occurs 346 in a quasi-two-dimensional thin parallelepiped cavity with dimensions $100 \mathrm{~mm}$ width $\times$

$34760 \mathrm{~mm}$ height. Initially, the melt inside the cavity is kept at a uniform temperature slightly above its 348 liquidus temperature. One of the lateral faces of the cavity is then cooled down while other faces are 
kept adiabatic (Figure 6). This solidification process mimics an experiment performed for the first time by Hebditch and Hunt ${ }^{[32]}$ for three binary alloys, one of which was $\mathrm{Sn}-5 \mathrm{wt} \% \mathrm{~Pb}$, to study the effect of buoyancy convection on macrosegregation. Since then the experiment has been modeled many times using models for columnar solidification ${ }^{[33,34]}$ as well as models that included motion of the equiaxed grain phase ${ }^{[35,36]}$. In our simulation, the initial temperature of the melt is $499.15 \mathrm{~K}$, with a small superheat of about $0.43 \mathrm{~K}$ above the liquidus temperature of the alloy. The outside temperature and heat transfer coefficient at the cooling face are $298.15 \mathrm{~K}$ and $300 \mathrm{~W} \mathrm{~m}^{-2} \mathrm{~s}^{-1}$, respectively. All thermophysical parameters and material properties are listed in Table IV, most of which are taken from the work ${ }^{[36]}$.

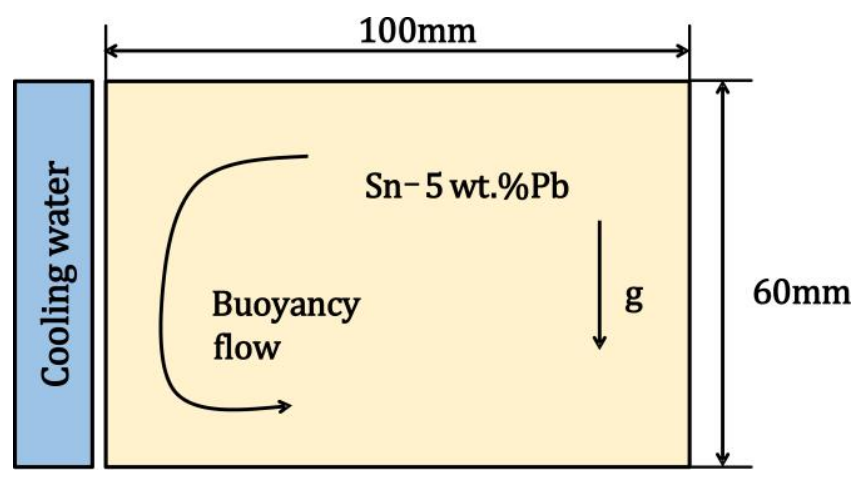

Fig. 6-Illustration for the solidification problem under consideration.

\section{Results and discussion}

For convenience, the simulation performed with diffusion length given by Eq. [35] and presented in this section IV.A is referred to hereafter as case A. To demonstrate the crucial effect of diffusion length on the resulting solidification pattern, a simulation presented in section IV.B and referred to as case B, is performed with the diffusion length given by Eq. [36]. Other internal parameters, material properties, and external conditions for cases A and B are identical.

\section{A. Results of case A}

At the beginning of the solidification process, the liquid next to the cooling side flows downwards due to the thermal and solutal buoyancy effects. Nucleation occurs once local undercooling is greater than nucleation undercooling. According to material properties (see Table IV), the solute-poor grains have higher mass density than liquid. Therefore, subjected to drag force and gravity, they are further transported by the fluid flow, sediment, and accumulate at the cavity bottom. In solidification, the partition coefficient for $\mathrm{Pb}$ is less than one, meaning that the solid initially forms at a depleted composition relative to the nominal one, and the solute is rejected into 

segregation phenomena become more pronounced.

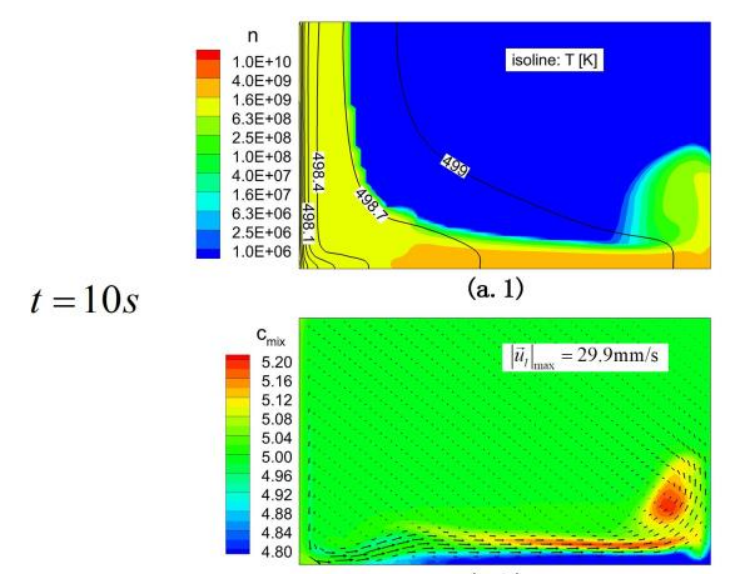

(a. 3)

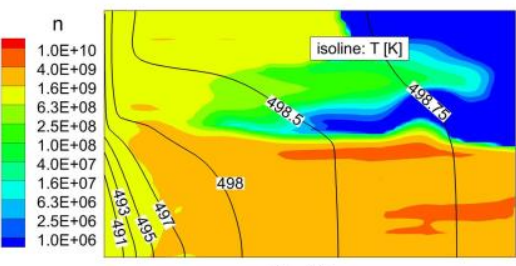

(b. 1)

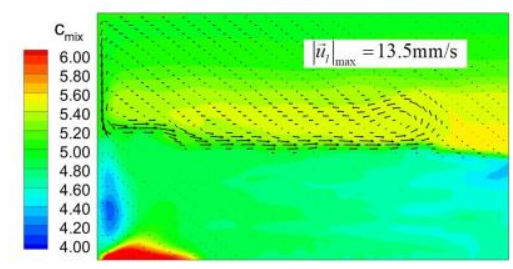

(b. 3)

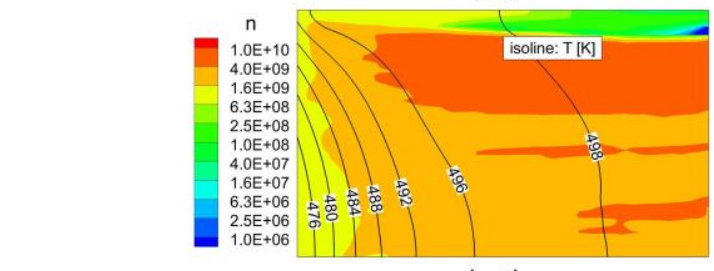

$t=250 \mathrm{~s}$

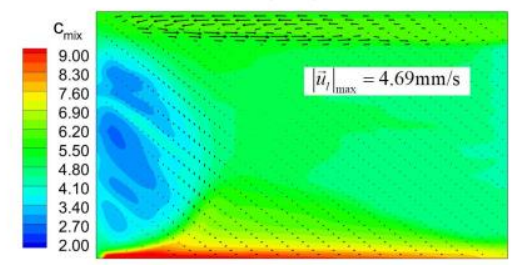

(c. 3)

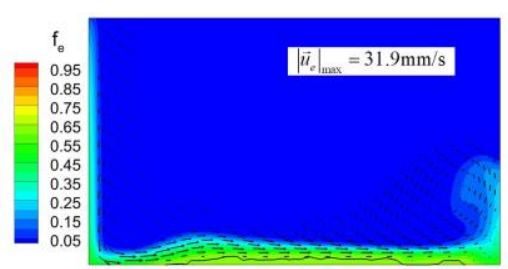

(a. 2)

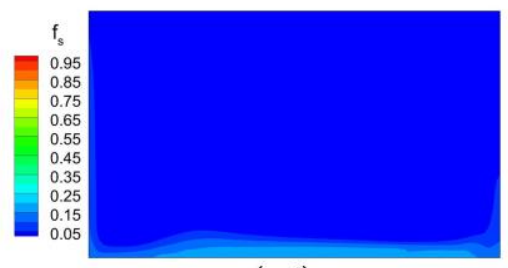

(a. 4)

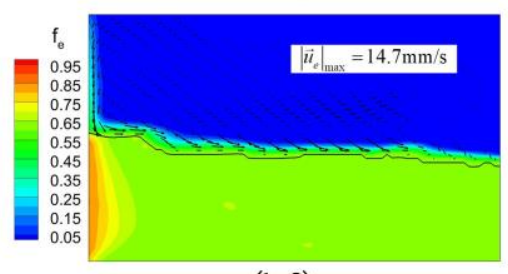

(b. 2)

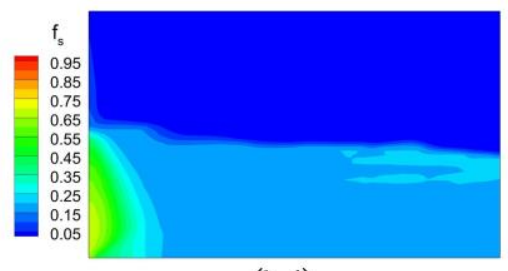

(b. 4)

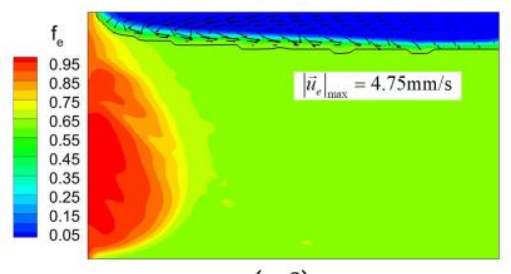

(c. 2)

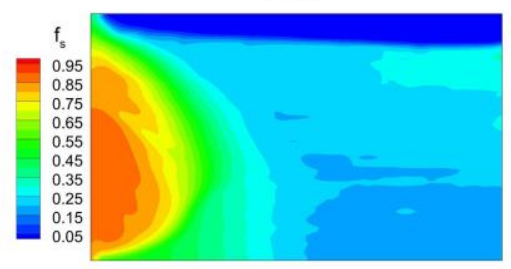

(c. 4)

Fig. 7-Various fields at different solidification times in case A: (a.1, b.1 and c.1) temperature and

380 grain number density ( $n$ in $\left.\mathrm{m}^{-3}\right),\left(\right.$ a.2, b.2 and c.2) grain phase fraction $\left(f_{e}\right)$ and velocity $\left(\vec{u}_{e}\right)$, the

381 black line shows the $f_{e}=0.637$ level, (a.3, b.3 and c.3) averaged solute concentration $\left(c_{\text {mix }}\right.$ in

382 wt. \% Pb) and liquid phase velocity $\left(\vec{u}_{l}\right)$, and (a.4, b.4 and c.4) solid phase fraction. 

fraction limit $f_{p}^{e}$, a packed region appears, which is shown below by the black line in Figure 7(a.2, b.2 and c.2). At 10s, only a thin layer of packed grains is formed at the bottom. When grains arrive at the right wall, they are dragged upwards by the liquid and tend to sediment at the same time, thus resulting in their slight backwards flow followed by their dispersion in the bulk liquid. The packed grain layer gradually piles up from the bottom of the cavity to the top. Some grains reach the packing fraction limit before arriving at the right wall, which explains the formation of a gentle slope towards the east (Figure 7(b.2 and c.2)). The upward liquid flow through the packed bed depletes its solute concentration and enriches the liquid layer above the bed (Figure 7(a.3 and b.3)).

392 The downward liquid flow in the packed porous zone brings the solute down, forming a small enriched pool at the bottom of the cavity (Figure 7(b.3)).

At 250 seconds of solidification, almost the entire cavity is occupied by packed grains, yet the extradendritic liquid still circulates between them. Due to the large flow resistance in the packed region, liquid flow in this area is weak, as shown in Figure 7(c.3), and maximum liquid flow velocity in the packed region is only $6.5 \times 10^{-4} \mathrm{~m} / \mathrm{s}$. However, this weak liquid flow can still influence solute distribution if sufficient time is provided. As can be seen further in Figure 8, due to buoyancy force and residual fluid flow, the enriched liquid descends and is replaced by the liquid from upstream. Continued enrichment at the bottom leads to strong positive segregation over the entire bottom. The overall result is that a region with semicircular shape forms near the cooling face, corresponding to a negative segregated region at the same place, while positive segregation forms in the bottom righthand region (Figure 7(c.3) and Figure 8). solidification model ${ }^{[33,34,39]}$, some segregation channels form near the cooling side. These channels are determined by thermosolutal buoyancy and the local fluctuations in permeability of the packed zone. Cells with higher solute content will have a lower liquidus temperature, and therefore, a lower solid fraction for a given temperature. Therefore, envelope growth can be accelerated at one

409 location, or suppressed at another location depending on the flow field and solute concentration

410 distribution. Fluctuation of envelope growth will influence the permeability term in the

411 momentum equation, and then further affect the flow field. This mechanism generates a positive 412 feedback loop, allowing channels to continue to grow. In Figure 8, average solute concentration 
distribution is overlaid with the vectors for velocity in the extradendritic liquid and isolines of the solid fraction for $f_{s}=0.5$ and $f_{s}=0.9$. Areas with lower composition correspond to the protrusions of the solid into the bulk fluid flow during the earlier solidification stage. Liquid flow is most intense near the isoline $f_{s}=0.5$ from the lefthand side, i.e. in the zone $f_{s}>0.5$. It is observed that a new channel appears on the existing channel from $t=400$ s to $t=550$ s (Figure 8). After that, channel formation stops but macrosegregation continue to evolve (compare Figure 8(b) and Figure 12).

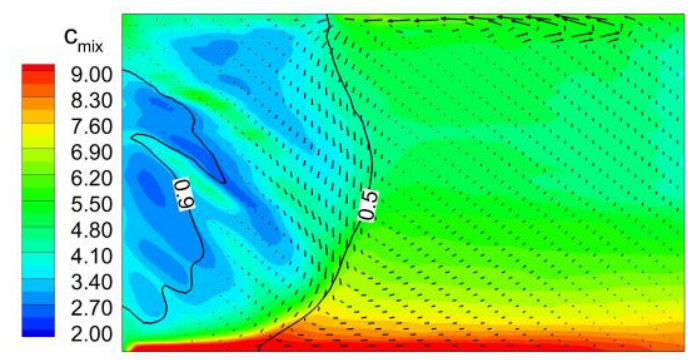

(a) $t=400 \mathrm{~s}\left|\vec{u}_{l}\right|_{\max }=4.69 \mathrm{~mm} / \mathrm{s}$

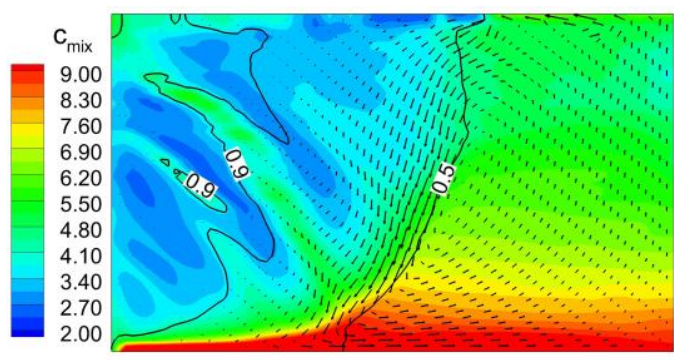

(b) $t=550 \mathrm{~s}\left|\vec{u}_{l}\right|_{\max }=0.65 \mathrm{~mm} / \mathrm{s}$

422 Fig. 8-Evolution of macrosegregation with most grains being packed: solute distribution is shown with isolines of the solid fraction and vectors for flow velocity in $l$-phase (case A).

\section{B. Results of case B}

Similar to case A, at the early stage of solidification of case B, the equiaxed grains appear and grow near the cooling side before sedimenting to the bottom, causing negative segregation (Figure 9(a.3, b.3 and c.3)). The equiaxed grains pile up to form a packed region near the bottom. Diffusion length in case B always increases as envelope growth velocity decreases, meaning that the diffuse flux from the interdendritic liquid to the extradendritic liquid decreases with time and that bulk liquid enrichment is much less intense compared to the previous case. A weak enrichment leads to a higher constitutional undercooling, thus the envelope growth rate of grains remains high even when they get packed. Consequently, the extradendritic liquid between the grains rapidly disappears (Figure 9(b.2 and c.2)), and its convective velocity approaches zero (Figure 9(c.3) and Figure 10). A slightly enriched layer of the extradendritic liquid still remains on the top of packed grain region, because the buoyancy term related to solute concentration is small and the permeability of the packed grain region rapidly decreases. Although there is still interdendritic liquid inside the grain phase, the current model assumes that it has the velocity of 

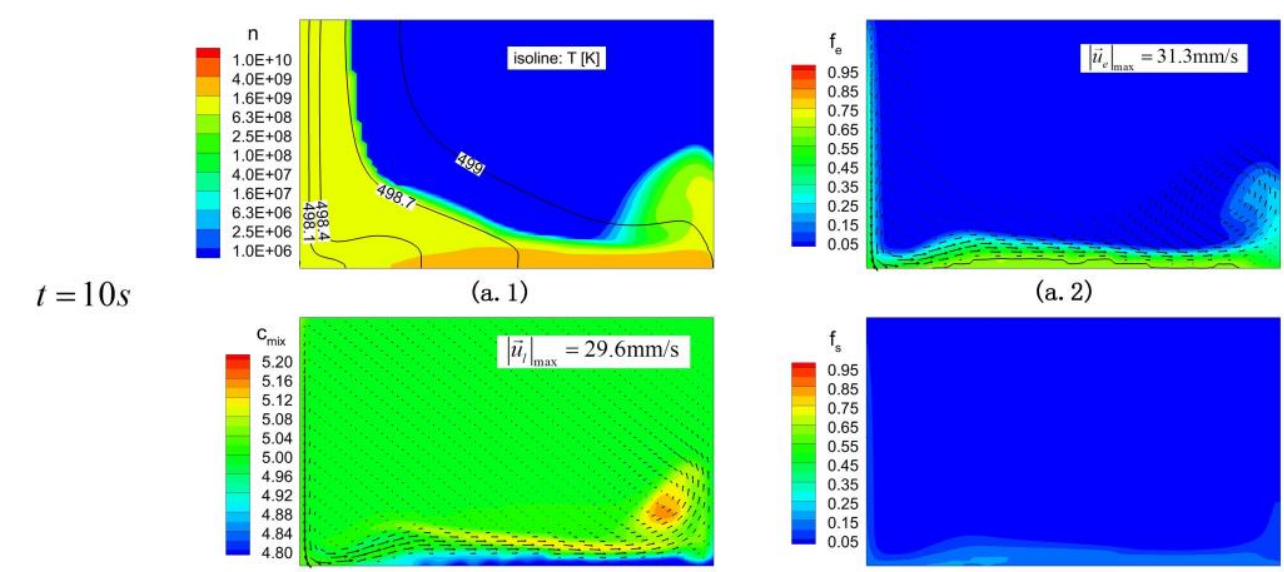

(a. 2)

(a. 3)

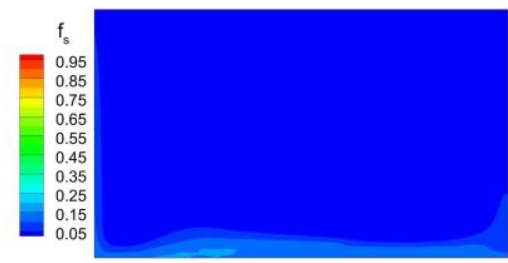

(a. 4)

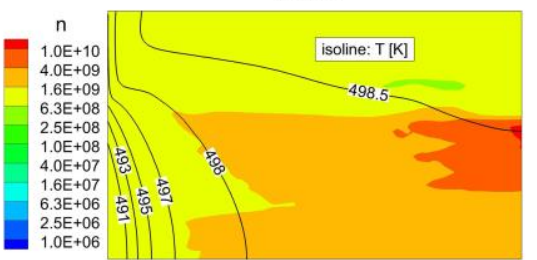

(b. 1)

$t=75 s$

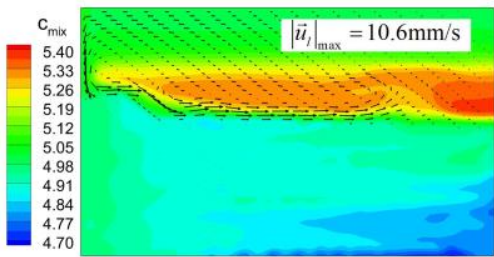

(b. 3)

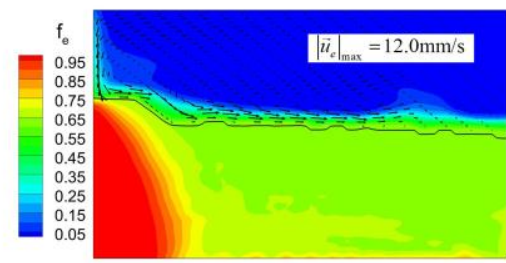

(b. 2)

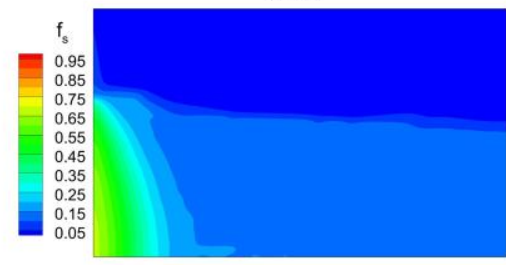

(b. 4)

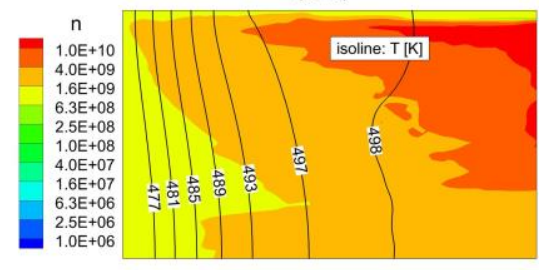

(c. 1)

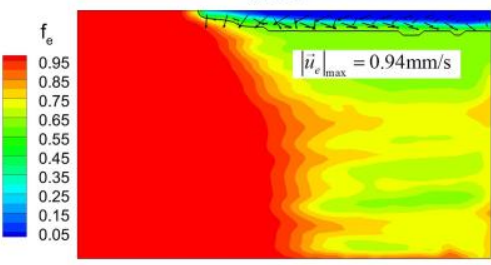

(c. 2)

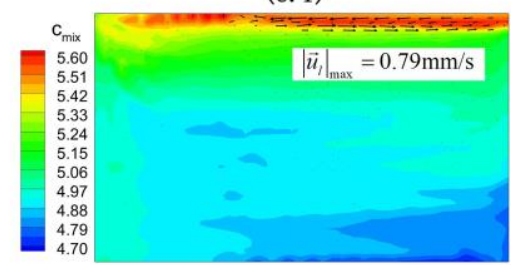

(c. 3)

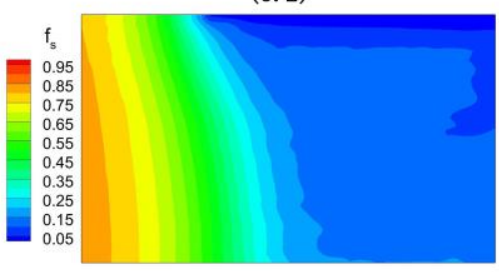

(c. 4)

Fig. 9-Various fields at different solidification times in case B: (a.1, b.1 and c.1) temperature and

441 grain number density $\left(n\right.$ in $\left.\mathrm{m}^{-3}\right),\left(\mathrm{a} .2, \mathrm{~b} .2\right.$ and c.2) grain phase fraction $\left(f_{e}\right)$ and velocity $\left(\vec{u}_{e}\right)$, the

442 black line shows the $f_{e}=0.637$ level, (a.3, b.3 and c.3) averaged solute concentration ( $c_{\mathrm{mix}}$ in

443 wt. \% Pb) and liquid phase velocity $\left(\vec{u}_{l}\right)$, and (a.4, b.4 and c.4) solid phase fraction.

445 the grain phase, yet, the latter is already packed, i.e. immovable. Therefore, after 250s, solute

446 distribution barely changes, as can be seen in Figure 10. Although solidification proceeds in a 
horizontal direction from the cooling side to the adiabatic side, slightly enriched liquid is then captured at the top by the packed grains whose fraction is not far from 1. Finally, an upward pointing concentration gradient forms in the sample (Figure 12(b)). For the same solidification

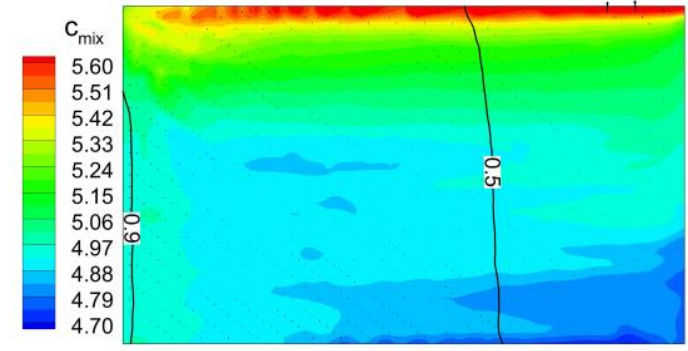

(a) $t=400 \mathrm{~s}\left|\vec{u}_{l}\right|_{\max }=0.16 \mathrm{~mm} / \mathrm{s}$

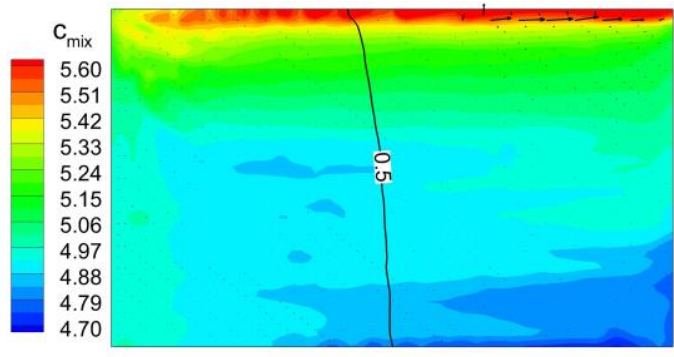

(b) $t=550 \mathrm{~s}\left|\vec{u}_{l}\right|_{\max }=0.08 \mathrm{~mm} / \mathrm{s}$

453 Fig. 10-Evolution of macrosegregation with most grains being packed: solute distribution is

454 shown with isolines of the solid fraction and vectors for flow velocity in $l$-phase (case B).

\section{Effect of the diffusion length model on solidification results}

During the early stage of solidification, case B shows similar phenomena to case A, yet at $75 \mathrm{~s}$, the two cases already present differences in grain growth and macrosegregation that become more pronounced with time.

A less intense enrichment of the extradendritic liquid and a higher grain growth velocity in case B lead to a faster increase in the height of the packed bed despite in this case a slower grain sedimentation velocity (compare Figures 7(b) and 8(b)). The packed bed grows fast at the beginning before slowing down due to the solidification process. In Figure 11, a height of the packed bed estimated from the results obtained by Založnik et al. ${ }^{[36]}$ with a two-phase model is also presented for comparison. The conclusion can be drawn that present three-phase models with the packing grain limit of 0.637 predict faster growth of the packed bed than the two-phase model with the packing limit of 0.3 for the solid fraction.

Similar to a columnar solidification, ${ }^{[33,34,39]}$ the channels are initiated near the cooling side and directed downwards following the fluid flow, which circumflexes the grains already packed at the lefthand wall, making the channels convex upward. For case B, the $l$-phase is quickly exhausted, meaning that the extradendritic liquid flow becomes too weak to affect solute distribution and to 
form channels. A comparison of Figure 8 and Figure 10 shows that solid growth in case B is

474

475

476

477

478

479

480

481

482

483

484

485

486

487

slower than in case A due to the faster diffusion of the solute from the solidifying dendrite to the

extradendritic liquid. This is conversely to the zero-dimension solidification case which was

considered in section II because the rejected solute is not conserved within a grain but is

redistributed in the bulk liquid. Finally, in case A, positive enrichment forms at the bottom

righthand part of the cavity, as shown in the macrosegregation map (Figure 12(a)), while in case B,

a discontinuous positive segregation chain is presented at the top (Figure 12(b)). The segregation

degree in case B is much smaller, from $4.8 \%$ to $5.8 \%$, than that in case A, from $1.9 \%$ to $13.4 \%$

(Figure 12).

It should be noted that the segregation pattern in case $\mathrm{A}$ is close to the original experimental result (except channels), ${ }^{[32]}$ although mainly columnar grain structure was found in the experiment.

This can be explained by the fact that in the present simulation, the dendrite equiaxed structure grows quickly before being packed into a bed that occupies the entire cavity. During further solidification, the packed grains cannot move anymore, and thus behave like a columnar dendrite structure.

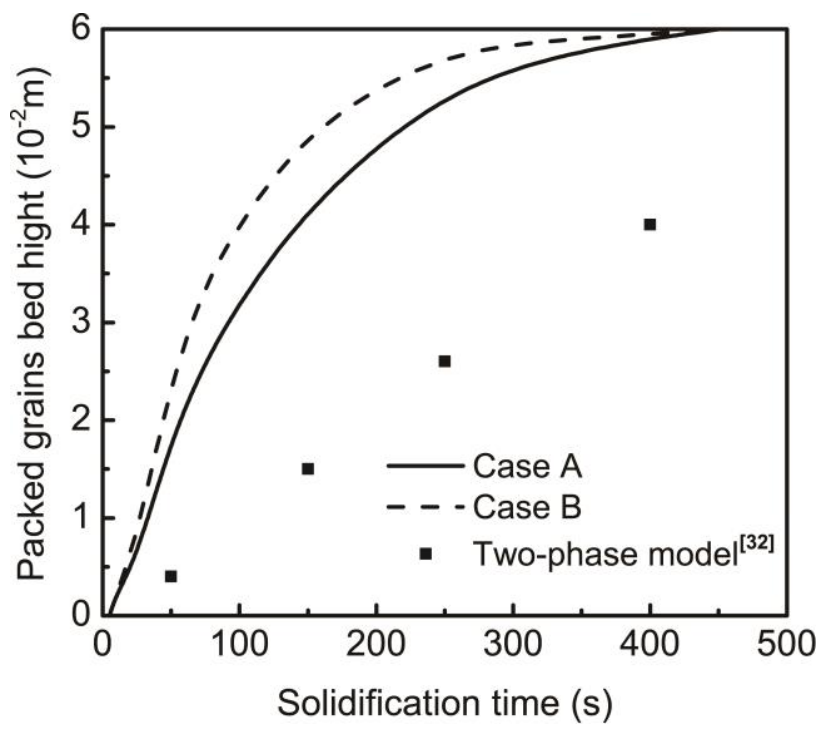

489 Fig. 11 - Comparison of packed grain bed evolution. 


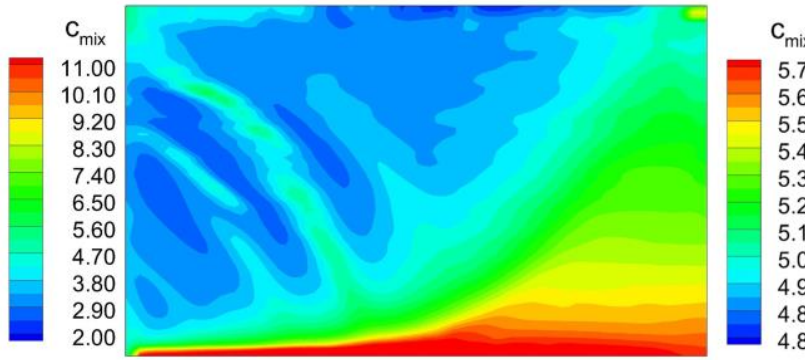

(a)

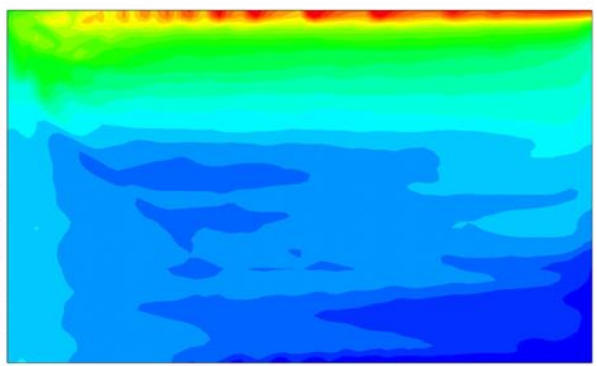

(b)
490

491

Fig. 12 - Segregation map for case A (a) and case B (b) at 1000s.

\section{Conclusions}

A modernized three-phase solidification model was proposed and applied for simulation of equiaxed dendritic solidification accounting for grain transport under the buoyancy flow. In the model, use of the Happel approximation for the momentum exchange coefficient between the two phases allows us to account for grain transport for the full grain fraction range. Furthermore, an additional criterion proposed for the treatment of the grain packing phenomenon allows us to take into account properly those grains whose fraction exceeds a theoretical packing limit but which were transported in the middle of the bulk liquid and, consequently, should not be blocked. However, the main novelty of the model is a new equation for calculation of diffusion length. The proposed diffusion length equation combines the factors affecting diffusion length in the extradendritic liquid, including a convective flow around the grains. The drastic effect of the adopted model is demonstrated with two simulations of the solidification of a binary alloy $\mathrm{Sn}-5 \mathrm{wt} \% \mathrm{~Pb}$. The only difference between them is in the calculation of diffusion length: case A uses a proposed equation, while case B uses a diffusion length purely dependent on envelope growth velocity. The numerical results show that the case including the proposed equation for diffusion length predicts a slower growth of the packed grain bed at the bottom of the cavity, formation of channels near the cooling side, and a final segregation pattern with an enriched layer at the bottom. The overall final segregation pattern is similar to the results obtained with the columnar model used earlier as well as with the experimental one. 


\section{ACKNOWLEDGMENTS}

513 This work is a joint cooperation between the SIMAP laboratory of Grenoble INP (France) and

514 the Key Laboratory of EPM of Northeastern University (P. R. China). The authors gratefully

515 acknowledge financial support from the National Nature Science Foundation of China (Grant No.

516 U1760206), the National Key R\&D Program of China (Grant No. 2017YFE0107900), the Project

517 of Introducing Talents of Discipline Innovation to Universities 2.0 (the 111 Project of China 2.0,

518 No. BP0719037) and China Scholarship Council (No. 201706080074). The SIMAP laboratory

519 acknowledges the financial support provided by the ESA-MAP MICAST project contract

$52014347 / 01 / \mathrm{NL} / \mathrm{SH}$.

521

522 


\begin{tabular}{|c|c|c|c|}
\hline \multicolumn{4}{|c|}{ NOMENCLATURE } \\
\hline$c_{i}$ & $\begin{array}{l}\text { solute concentration in } i \text { - phase } \\
\text { (wt. } \% \text { ) }\end{array}$ & $S_{e}^{J}$ & $\begin{array}{l}\text { diffusion surface concentration of the } \\
\text { grain phase }\left(\mathrm{m}^{-1}\right)\end{array}$ \\
\hline$c_{\text {mix }}$ & mix solute concentration (wt.\%) & $t$ & time (s) \\
\hline$c_{\text {eut }}$ & eutectic concentration (wt.\%) & $T$ & temperature $(\mathrm{K})$ \\
\hline$c_{l}^{*}, c_{s}^{*}$ & $\begin{array}{l}\text { equilibrium concentration at } f-s \text { or } \\
d \text {-s interface (wt. } \% \text { ) }\end{array}$ & $T_{\text {eut }}$ & eutectic temperature $(\mathrm{K})$ \\
\hline$c_{e n v}$ & concentration at $l-d$ interface (wt.\%) & $T_{0}$ & initial temperature $(\mathrm{K})$ \\
\hline$c_{p}^{i}$ & specific heat for $i$-phase $\left(\mathrm{Jg}^{-1} \mathrm{~K}^{-1}\right)$ & $\Delta T$ & constitutional undercooling $(\mathrm{K})$ \\
\hline$c_{0}$ & initial concentration (wt.\%) & $\Delta T_{\text {nucl }}$ & nucleation temperature $(\mathrm{K})$ \\
\hline$d_{e}, d_{s}$ & grain diameter $(\mathrm{m})$ & $\vec{u}_{i}$ & velocity vector of $i$ - phase $\left(\mathrm{m} \mathrm{s}^{-1}\right)$ \\
\hline$D_{l}$ & $\begin{array}{l}\text { diffusion coefficient in liquid } \\
\left(\mathrm{m}^{2} \mathrm{~s}^{-1}\right)\end{array}$ & $\vec{U}_{i j}^{D}$ & $\begin{array}{l}\text { momentum transfer rate from } i \text { - phase } \\
\text { to } j \text { - phase }\left(\mathrm{kg} \mathrm{m}^{-2} \mathrm{~s}^{-2}\right)\end{array}$ \\
\hline$f_{\mathrm{i}}$ & volume fraction of $i$ - phase (1) & $v_{\text {env }}$ & envelope growth velocity $\left(\mathrm{m} \mathrm{s}^{-1}\right)$ \\
\hline$f_{p}^{e}, f_{p}^{s}$ & packing limit fraction (1) & $v_{d s}$ & $d-s$ interface growth velocity $\left(\mathrm{m} \mathrm{s}^{-1}\right)$ \\
\hline$f_{s}^{e}$ & solid fraction within grains (1) & \multicolumn{2}{|c|}{ Greek Symbols } \\
\hline$\vec{F}_{B i}$ & $\begin{array}{l}\text { buoyancy force of } i \text { - phase } \\
\left(\mathrm{kg} \mathrm{m}^{-2} \mathrm{~s}^{-2}\right)\end{array}$ & $\beta_{T}$ & thermal expansion coefficient $\left(\mathrm{K}^{-1}\right)$ \\
\hline$h_{i}$ & enthalpy of of $i$ - phase $\left(\mathrm{J} \mathrm{kg}^{-1}\right)$ & $\beta_{c}$ & solutal expansion coefficient (1) \\
\hline$H^{*}$ & $\begin{array}{l}\text { interfacial heat transfer coefficient } \\
\left(\mathrm{W} \mathrm{m}{ }^{-3} \mathrm{~K}^{-1}\right)\end{array}$ & $\Phi_{\mathrm{M}}$ & $\begin{array}{l}\text { shape factor of dendritic envelope } \\
\text { growth (1) }\end{array}$ \\
\hline$J_{i j}$ & $\begin{array}{l}\text { species transfer rate from } i \text { - phase to } \\
j \text { - phase }\left(\mathrm{m} \mathrm{s}^{-1}\right)\end{array}$ & $\Phi_{\mathrm{J}}$ & sphericity of dendritic envelope (1) \\
\hline$k_{i}$ & $\begin{array}{l}\text { thermal conductivity for } i \text {-phase } \\
\left(\mathrm{W} \mathrm{m}^{-1} \mathrm{~K}^{-1}\right)\end{array}$ & $\Gamma$ & gibbs thomson coefficient (m K) \\
\hline$k$ & solute partition coefficient (1) & $\lambda_{2}$ & secondary arm spacing $(\mathrm{m})$ \\
\hline$K_{i j}$ & $\begin{array}{l}\text { liquid-equiaxed drag coefficient } \\
\left(\mathrm{kg} \mathrm{m}^{-3} \mathrm{~s}^{-1}\right)\end{array}$ & $\mu_{i}$ & viscosity of $i$ - phase $\left(\mathrm{kg} \mathrm{m}^{-1} \mathrm{~s}^{-1}\right)$ \\
\hline$l_{i}$ & diffusion length of $i$ - phase (m) & $\rho_{i}$ & density of $i$ - phase $\left(\mathrm{kg} \mathrm{m}^{-3}\right)$ \\
\hline$L$ & latent heat $\left(\mathrm{J} \mathrm{kg}^{-1}\right)$ & $\rho_{\text {ref }}$ & reference density $\left(\mathrm{kg} \mathrm{m}^{-3}\right)$ \\
\hline$m$ & $\begin{array}{l}\text { slope of liquidus in phase diagram } \\
\text { (K) }\end{array}$ & $\rho_{s}^{b}$ & density of solid phase for buoyancy \\
\hline$M_{\Phi}$ & $\begin{array}{l}\text { mass transfer rate from nucleation } \\
\left(\mathrm{kg} \mathrm{m}^{-3} \mathrm{~s}^{-1}\right)\end{array}$ & $\Psi_{i}$ & a intensive medium property (-) \\
\hline$M_{i j}$ & $\begin{array}{l}\text { mass transfer rate from } i \text { - phase to } \\
j \text { - phase }\left(\mathrm{kg} \mathrm{m}^{-3} \mathrm{~s}^{-1}\right)\end{array}$ & \multicolumn{2}{|c|}{ Subscripts } \\
\hline$n_{\max }$ & $\begin{array}{l}\text { maximum equiaxed grain density } \\
\left(\mathrm{m}^{-3}\right)\end{array}$ & $d$ & interdendritic liquid phase \\
\hline
\end{tabular}




$\begin{array}{llll}n & \text { grain number density }\left(\mathrm{m}^{-3}\right) & e: d+s & \text { exquiaxed grain phase } \\ N_{\Phi} & \text { nuclei production rate }\left(\mathrm{m}^{-3} \mathrm{~s}^{-1}\right) & f: l+d & \text { liquid phase } \\ R e & \text { Reynolds number (1) } & l & \text { extradendritic liquid phase } \\ S h & \text { Sherwood number (1) } & s & \text { interdendritic solid phase } \\ S_{e}^{M} & \text { surface concentration of the } & & \\ & \text { equivalent sphere }\left(\mathrm{m}^{-1}\right) & & \end{array}$

523 Note:

524 The symbols related to averaging procedures are omitted in the paper, i.e. a field property

525 averaged over its proper phase $\left\langle\Psi_{i}\right\rangle^{i}$ is replaced with $\Psi_{i}$ for simplicity. 
M. Wu, L. Könözsy, A. Ludwig, W. Schützenhöfer, and R. Tanzer: Steel Res. Int., 2008, vol. 79, pp. 637-

44.

M. Wu, A. Ludwig, and A. Kharicha: Metals (Basel)., 2019, vol. 9, p. 229.

N. Leriche, H. Combeau, C.A. Gandin, and M. Založnik: IOP Conf. Ser. Mater. Sci. Eng., 2015, vol. 84, pp. $1-8$. 122, pp. 939-53. M. Rappaz and P.H. Thévoz: Acta Metall., 1987, vol. 35, pp. 2929-33. M. Wu, A. Ludwig, A. Bührig-Polaczek, M. Fehlbier, and P.R. Sahm: Int. J. Heat Mass Transf., 2003, vol. 46, pp. 2819-32. J. Ni and C. Beckermann: Metall. Trans. B, 1991, vol. 22, pp. 349-61. M. Wu and A. Ludwig: Acta Mater., 2009, vol. 57, pp. 5632-44. J. Happel: AIChE J., 1958, vol. 4, pp. 197-201. M.J.M. Krane: Appl. Math. Model., 2004, vol. 28, pp. 95-107. 12907.

A. Olmedilla, M. Založnik, B. Rouat, and H. Combeau: Phys. Rev. E, 2018, vol. 97, p. 012910. D.J. Hebditch and J.D. Hunt: Met. Trans, 1974, vol. 5, pp. 1557-64.

3 N. Ahmad, J. Rappaz, J.-L. Desbiolles, T. Jalanti, M. Rappaz, H. Combeau, G. Lesoult, and C. Stomp: Metall. Mater. Trans. A, 1998, vol. 29, pp. 617-30.

A. Kumar, B. Dussoubs, M. Založnik, and H. Combeau: J. Phys. D. Appl. Phys., 2009, vol. 42, p. 105503.

35 T.-T.-M. Nguyen, C.-A. Gandin, H. Combeau, M. Založnik, and M. Bellet: Metall. Mater. Trans. A, 2018, vol. 49, pp. 1725-48. 
$570 \quad 37$

$571 \quad 38$

$572 \quad 39$

573

574

575

576

577

A. Plotkowski and M.J.M. Krane: Comput. Mater. Sci., 2016, vol. 124, pp. 238-48.

A. Plotkowski and M.J.M. Krane: Int. J. Heat Mass Transf., 2016, 100, vol. 100. Int. J. Heat Mass Transf., 2016, vol. 100, pp. 680-90.

40 T. Carozzani, C.-A. Gandin, H. Digonnet, M. Bellet, K. Zaidat, and Y. Fautrelle: Metall. Mater. Trans. A, 2013, vol. 44, pp. 873-87. 


\section{Caption list}

579 Fig.1. (a) Schematic representation of grain growth with phase assignment, and (b)effect of diffusion length on average solute concentration in each phase.

Table I. Diffusion length ahead of the dendrite tip in equiaxed solidification models

Fig.2. Schematic figure for different unions of phases: (a) solid dendrite (s- phase) and liquid phase (f-phase), (b) equiaxed grain phase (e-phase) and extradendritic liquid phase (1phase), and (c) the solid dendrite (s-phase), inter- and extradendritic liquid phases (d- and 1-phases).

Table II. Coefficient in the equation for the momentum exchange, Eq. [2].

Table III. Conservation equations, source terms, and auxiliary expressions.

Fig.3. Solidification in a zero dimension uniformly solidifying system obtained with different models (Eqs. [35] through [38]) for diffusion length $l_{l}$ : (a) variation of diffusion length $l_{l}$ in time, (b) evolution of the solid and grain fractions and (c) temperature evolution.

Fig. 4. Comparison of (a) dimensionless momentum exchange coefficient between 1- and ephases and (b) settling velocity between different models.

Fig. 5. Scheme algorithm scheme.

Fig. 6. Illustration for the solidification problem under consideration.

Table IV. Phase diagram data and Material properties.

Fig. 7. Various fields at different solidification times in case A: (a.1, b.1 and c.1) temperature and grain number density ( $n$ in $\left.\mathrm{m}^{-3}\right),\left(\right.$ a.2, b.2 and c.2) grain phase fraction $\left(f_{e}\right)$ and velocity $\left(\vec{u}_{e}\right)$, the black line shows the $f_{e}=0.637$ level, (a.3, b.3 and c.3) averaged solute concentration $\left(c_{\text {mix }}\right.$ in wt. \% Pb) and liquid phase velocity $\left(\vec{u}_{l}\right)$, and (a.4, b.4 and c.4) solid phase fraction.

Fig. 8. Evolution of macrosegregation with most grains being packed: solute distribution is shown with isolines of the solid fraction and vectors for flow velocity in $l$-phase (case A).

Fig.9. Various fields at different solidification times in case B: (a.1, b.1 and c.1) temperature and grain number density $\left(n\right.$ in $\left.\mathrm{m}^{-3}\right),\left(\mathrm{a} .2, \mathrm{~b} .2\right.$ and c.2) grain phase fraction $\left(f_{e}\right)$ and velocity $\left(\vec{u}_{e}\right)$, the black line shows the $f_{e}=0.637$ level, (a.3, b.3 and c.3) averaged solute concentration $\left(c_{\text {mix }}\right.$ in wt. $\% \mathrm{~Pb})$ and liquid phase velocity $\left(\vec{u}_{l}\right)$, and (a.4, b.4 and c.4) solid phase fraction.

Fig. 10. Evolution of macrosegregation with most grains being packed: solute distribution is shown with isolines of the solid fraction and vectors for flow velocity in $l$-phase (case B).

Fig. 11. Comparison of the packed grains bed evolution.

Fig. 12. Segregation map for case A (a) and case B (b) at 1000s. 


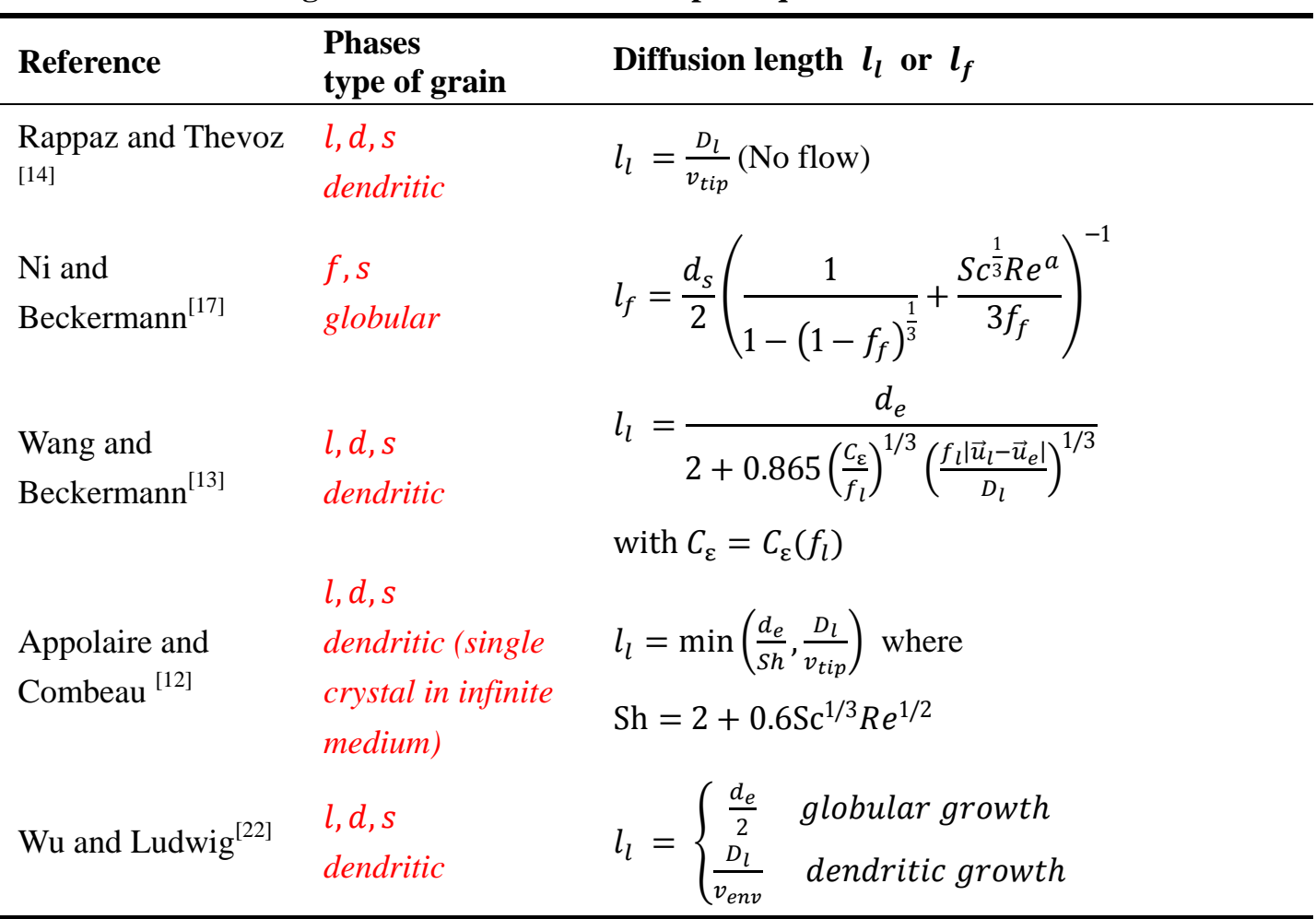

613

614 


\begin{tabular}{|c|c|c|}
\hline Reference & $\begin{array}{l}\text { Phases, union of } \\
\text { phases, } \\
\text { type of grain }\end{array}$ & Coefficients for Eq. [2] \\
\hline $\begin{array}{l}\text { Wu and } \\
\text { Ludwig }^{[22]}\end{array}$ & $\begin{array}{l}l, e=(d \cup s) \\
\text { dendritic }\end{array}$ & $K_{l e}=F_{k}\left(f_{l}, d_{e}\right) \frac{\mu_{l}}{K}= \begin{cases}\frac{180 \mu_{l} f_{e}^{2}}{f_{l} d_{e}^{2}} & f_{e}<f_{s c} \\
\frac{\mu_{l} f_{l}^{2}}{K} & f_{e}>f_{s c}\end{cases}$ \\
\hline $\begin{array}{l}\text { Ni and } \\
\text { Beckermann }{ }^{[17]}\end{array}$ & $\begin{array}{l}f, s \\
\text { globular }\end{array}$ & $\begin{array}{l}F_{C D}=\frac{3}{4} \frac{f_{s}}{d_{s}}, \quad C_{D}=\frac{48 C_{k e}\left(1-f_{f}\right)}{R e}+C_{i e} \\
R e=\frac{\rho f_{f} d_{s}}{\mu_{f}}\left|\vec{u}_{f}-\vec{u}_{s}\right| \\
C_{k e}=0.5 \text { and } C_{\mathrm{ie}}=7 / 3 \text { for } f_{f} \leq 0.5 \\
C_{k e}\left(f_{f}, R e\right), \quad C_{i e}\left(f_{f}, R e\right) \text { for } f_{f}>0.5\end{array}$ \\
\hline $\begin{array}{l}\text { Wang and } \\
\text { Beckermann }{ }^{[13]}\end{array}$ & $\begin{array}{l}l, d, s \\
\text { dendritic }\end{array}$ & $\begin{array}{c}K_{f S}=4 f_{f}^{2} \beta^{2} \frac{\mu_{l}}{d_{e}^{2}} \quad \text { where } \\
\beta=\frac{\beta_{d}}{\left[\left(1-f_{l}\right)^{n}+\left(\beta_{d} / \beta_{l}\right)^{2 n}\right]^{1 / 2 n}}\end{array}$ \\
\hline $\begin{array}{l}\text { Apollaire and } \\
\text { Combeau }^{[12]}\end{array}$ & $\begin{array}{l}l, d, s \\
\text { dendritic } \\
\text { (single crystal in } \\
\text { infinite medium) }\end{array}$ & $\begin{array}{l}F_{C D}=\frac{\rho_{f} \pi d^{2} \Omega}{8}, C_{D}=\frac{C_{D}^{\prime}}{1.2376 \log (\Phi / 0.1556)} \quad \text { where } \\
C_{D}^{\prime}(R e), \Omega\left(\frac{\mathrm{d}}{\sqrt{K}}\right), \Phi \text { sphericity, } K \text { from Kozeny-Carman }\end{array}$ \\
\hline $\begin{array}{l}\text { Leriche and } \\
\text { Combeau }\end{array}$ & $\begin{array}{l}f=(l \cup d), s \\
\text { dendritic }\end{array}$ & $\begin{array}{l}\text { Slurry region: } F_{C D}=\frac{3 \rho}{4} \frac{f_{e}}{d_{e}} \quad C_{D}=\frac{48 C_{k e}\left(1-f_{l}\right)}{R e}+C_{i e} \\
C_{k e}=0.5 \text { and } C_{\mathrm{ie}}=7 / 3 \text { for } f_{e}>0.5 \\
C_{k e}\left(f_{l}, R e\right), C_{i e}\left(f_{l}, R e\right) \text { for } f_{e} \leq 0.5 \\
\text { Packed region: } K=\frac{\lambda_{2}^{2}}{20 \pi^{2}} \frac{f_{f}^{3}}{\left(1-f_{f}\right)^{2}}\end{array}$ \\
\hline
\end{tabular}




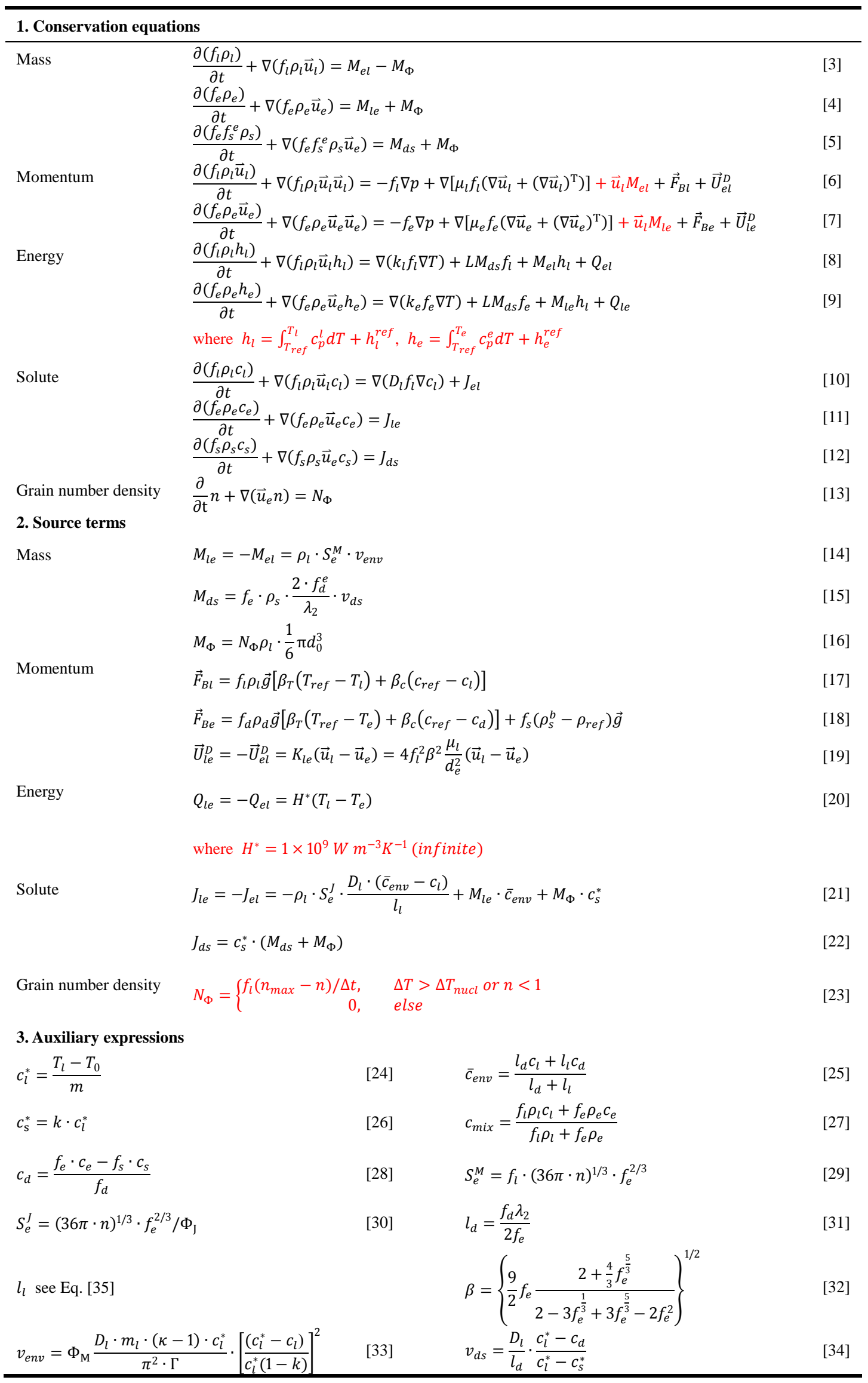




\begin{tabular}{|c|c|c|c|c|}
\hline & Symbol & Units & Value & Ref. \\
\hline \multicolumn{5}{|l|}{ Phase diagram } \\
\hline Melting temperature of pure $\mathrm{Sn}$ & $T_{S n}$ & $\mathrm{~K}$ & 505.15 & \\
\hline Eutectic temperature & $T_{\text {eut }}$ & $\mathrm{K}$ & 456.15 & \\
\hline Partition coefficient & $k$ & 1 & 0.0656 & {$[36]$} \\
\hline Initial solute concentration $(\mathrm{Pb})$ & $c_{0}$ & wt. \% & 5.0 & \\
\hline Liquidus slope & $m$ & $\mathrm{~K}$ & -128.6 & [36] \\
\hline \multicolumn{5}{|l|}{ Material properties } \\
\hline Reference mass density & $\rho_{\text {ref }}$ & $\mathrm{kg} \mathrm{m}^{-3}$ & 7000 & {$[36]$} \\
\hline Density of solid for buoyancy force & $\rho_{s}^{b}$ & $\mathrm{~kg} \mathrm{~m}^{-3}$ & 7143 & {$[36]$} \\
\hline Reference temperature for density & $T_{\text {ref }}$ & $\mathrm{K}$ & 499.15 & \\
\hline Liquid solutal expansion coefficient & $\beta_{c}$ & wt. $\%^{-1}$ & $5.3 \times 10^{-3}$ & [36] \\
\hline Liquid thermal expansion coefficient & $\beta_{T}$ & $\mathrm{~K}^{-1}$ & $6.0 \times 10^{-5}$ & {$[36]$} \\
\hline $\begin{array}{l}\text { Reference solute concentration for } \\
\text { density }\end{array}$ & $c_{r e f}$ & wt. \% & 5.0 & \\
\hline Specific heat & $c_{p}^{l}, c_{p}^{e}$ & $\mathrm{~J} \mathrm{~kg}^{-1} \mathrm{~K}^{-1}$ & 260 & {$[36]$} \\
\hline Thermal conductivity & $k_{l}, k_{e}$ & $\mathrm{~W} \mathrm{~m}^{-1} \mathrm{~K}^{-1}$ & 55 & {$[36]$} \\
\hline Latent heat & $L$ & $\mathrm{~J} \mathrm{~kg}^{-1}$ & 61000 & {$[36]$} \\
\hline Diffusion coefficient for liquid & $D_{l}$ & $\mathrm{~m}^{2} \mathrm{~s}^{-1}$ & $1 \times 10^{-8}$ & {$[36]$} \\
\hline Dynamic viscosity & $\mu_{l}, \mu_{e}$ & $\mathrm{~kg} \mathrm{~m}^{-1} \mathrm{~s}^{-1}$ & 0.001 & {$[36]$} \\
\hline Volume heat transfer coefficient & $H^{*}$ & $\mathrm{~W} \mathrm{~m}^{-3} \mathrm{~K}^{-1}$ & $1 \times 10^{9}$ & [21] \\
\hline Gibbs -Thomson coefficient & $\Gamma$ & $\mathrm{m} \mathrm{K}$ & $2 \times 10^{-7}$ & {$[40]$} \\
\hline Maximum grain number density & $n_{\max }$ & $\mathrm{m}^{-3}$ & $1 \times 10^{9}$ & {$[36]$} \\
\hline Initial grain diameter & $d_{0}$ & $\mathrm{~m}$ & $1 \times 10^{-6}$ & \\
\hline Secondary arm spacing & $\lambda_{2}$ & $\mathrm{~m}$ & $9 \times 10^{-5}$ & \\
\hline Shape factor for dendrite growth & $\Phi_{\mathrm{M}}$ & 1 & 0.683 & {$[22]$} \\
\hline Sphericity & $\Phi_{\mathrm{J}}$ & 1 & 0.283 & [22] \\
\hline Packing limit fraction & $f_{p}^{e}$ & 1 & 0.637 & {$[22]$} \\
\hline
\end{tabular}

